\title{
Kapitel 2: Die byzantinischen Heiligenviten
}

\author{
$\S 1$. Entstehung und Verwendung
}

\section{A. Die Sammlungen}

Die Frage nach der Entstehung und Verwendung der Heiligenviten als literarische Gattung läßt sich in erster Linie aus dem überlieferten handschriftlichen Bestand erschließen:

Albert Ehrhard hatte in seinen umfangreichen Untersuchungen zur Überlieferung der hagiographischen und homiletischen Literatur der griechischen Kirche auf der Grundlage der Betrachtung von rund $2.750 \mathrm{Hss}^{1}{ }^{1}$ eine recht eindeutige Lage des überlieferten handschriftlichen Bestands festgestellt. Demnach sind nicht nur die in der Einleitung angesprochenen Kurzviten aus den Synaxaren, sondern auch die überwiegende Mehrzahl der in dieser Arbeit vorrangig behandelten längeren und elaborierten Viten in sogenannten liturgischen Sammlungen (Jahressammlungen, Halbjahres-, Dritteljahres-, Vierteljahresmenologien, Zweimonats- und Monatsmenologien) ${ }^{2}$, seltener in hagiographischen Sammelhandschriften (hagiographische Codices, sogenannte nichtmenologische Sammlungen $)^{3}$ und nur vereinzelt auf anderem Wege ${ }^{4}$ überliefert.

Aufgrund dieser Situation konstatierte Ehrhard zunächst eine vorrangige Verwendung der Heiligenviten in der Liturgie durch die öffentliche Vorlesung in Kirchen, vor allem im Rahmen der üblichen Nachtwachen (Pannychides) vor den großen Festtagen oder aus Anlaß der alljährlich wiederkehrenden Gedenkfeier (Panegyris) für den Heiligen ${ }^{5}$. Dies ist hier besonders für den in dieser Arbeit untersuchten Zeitraum (7.-11. Jh.) noch einmal deutlich zu unterstreichen. ${ }^{6}$

Der an eine bestimmte Zuhörerschaft, also etwa die Gemeinde oder Mönchsgemeinschaft, gerichtete mündliche Vortrag der Heiligenviten ${ }^{7}$ hat auch recht häufig in den Texten selbst seine Spuren hinterlassen. Einige Beispiele mögen dies illustrieren:

\footnotetext{
1 Vgl. Ehrhard, Überlieferung I, XVII.

2 Vgl. Ehrhard, Überlieferung I, 154-701.

3 Vgl. Ehrhard, Überlieferung I, 146-153; III, 723-942.

4 Vgl Ehrhard, Uberlieferung III, 942-1033.
} 
Die Zuhörer werden etwa in der Vita des Georgios von Amastris (BHG 668) direkt angesprochen ${ }^{8}$. Der Verfasser verspricht dort, sich kurz zu fassen, damit

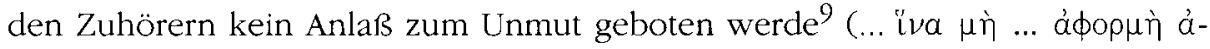
vías toîs ákpoataîs émı

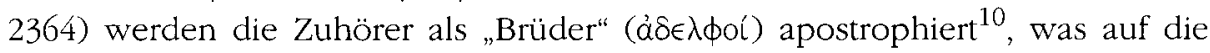
Verwendung dieser Vita in einem monastischen Kontext verweist. Auch in der Vita des Niketas von Medikion (BHG 1341) werden die Zuhörer angesprochen $^{11}$ : „O, heilige Zuhörerschaft!“ ( $\hat{\omega}$ iєрòv ảkpoatńpıov). Diese Ausdrucksweise läßt offen, ob es sich um ein potentielles Mönchs- oder auch Laienpublikum handelte. Im Proöm der Vita seiner Mutter Theoktiste (BHG 2422) spricht Theodoros Studites die Zuhörer, nämlich wiederum seine Mönche, folgendermaßen an ${ }^{12}$ : „Leiht mir nun euer Gehör, meine Söhne, und ich will euch berich-

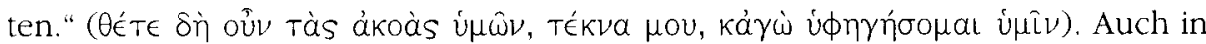
der Vita des Eustratios (BHG 645) spricht der Verfasser bzw. der Vortragende sein Auditorium direkt an ${ }^{13}$ : „O, das Heilige liebende Versammlung und Christus

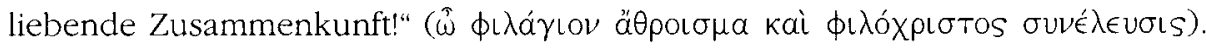

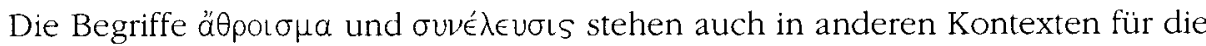
Versammlung der Gläubigen in der Kirche. In der Vita des Euthymios von

5 Vgl. Ehrhard, Überlieferung I, 19 mit Anm. 1; zur „Pannychis" vgl. Onasch, Ostkirche 283f. s. v "Nachtwache“; zur „Panegyris" vgl. Delehaye, Sanctus 123-125; Aigrain, Hagiographie $126 \mathrm{f}$ 166f. 239f.; Vryonis, Panegyris 196-228; Franklin, Latin Dossier 153; zur liturgischen Verwendung vgl. Delehaye, Sanctus 189-196; Angenendt, Heilige 129f; Franklin, Latin Dossier 152 154. Am Anfang stand mitunter vielleicht auch die Vorlesung zum Anlaß der Begräbnisfeierlichkeiten, vgl. S. Efthymiadis, in: Vita Tarasii (BHG 1698) 47: zur Vita Nicephori patriarchae (BHG 1335). S. dazu noch unten S. 378-382.

6 Es versteht sich von selbst und war natürlich auch Ehrhard klar, vgl. Überlieferung I, 18-25, bes. $19 \mathrm{Anm}$. 3, daß Sammlungen erst zu einem Zeitpunkt zusammengestellt werden konnten, an dem bereits genügend einzelne Stücke vorhanden waren. Das bedeutet, daß die Entstehung einzelner Viten der Entstehung von Sammlungen normalerweise vorausging (im Einzelfall wird es Abweichungen gegeben haben: die eine oder andere Vita könnte auch direkt für eine zu kompilierende Sammlung geschrieben worden sein), s. dazu auch noch im folgenden. Für den hier betrachteten Zeitraum können jedoch die Existenz und Verbreitung von Sammlungen bereits ohne Vorbehalt vorausgesetzt werden, so daß auch die daraus gezogenen Schlüsse in jedem Fall für den untersuchten Zeitraum gelten. Zu den Sammlungen vgl. auch Dummer, Hagiographie $292 \mathrm{f}$.

$7 \mathrm{Vgl}$. dazu auch Efthymiadis, Hagiographer and Audience 64-69; Auzépy, Hagiographie 10; Franklin, Latin Dossier $153 \mathrm{f}$.

8 Vita Georg. Amastr. (BHG 668) cap. 2, p. 3,3-9

9 Zu dieser Brevitas-Formel s. oben, Erster Teil, Kap. 1: „Prooimia“ sowie Kap. 16: „Epilogoi“.

10 Vita Petri Atroënsis (BHG 2364) cap. 4,38, p. 77.

11 Vita Nicet. Medic. (BHG 1341) cap. 1, p. XVIII.

12 Theod. Stud., Laud. matris (BHG 2422) cap. 1, col. 884B

13 Vita Eustratii (BHG 645) cap. 1, p. 367,1. 
Sardeis (BHG 2145) behauptet der Verfasser bzw. Vortragende, sich mitten unter die Zuhörer begeben zu haben, um das Leben des Heiligen zu erzählen ${ }^{14}$ :

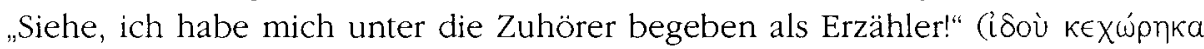

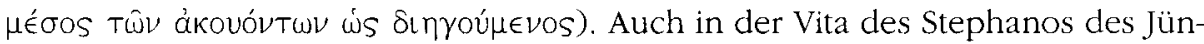
geren (BHG 1666) spricht der Verfasser bzw. Vortragende sein Publikum an ${ }^{15}$ :

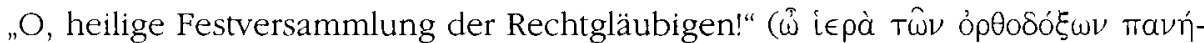

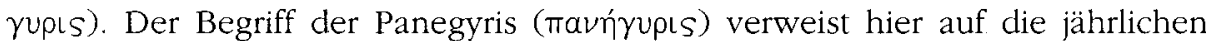
Gedenkfeiern des Heiligen an seiner Kultstätte. ${ }^{16}$ Dies sind nur einige wenige von zahlreichen Beispielen, die den mündlichen Vortrag der Heiligenviten bele$\operatorname{gen}^{17}$.

Die Verwendung der Heiligenviten als Vorlage für den mündlichen Vortrag

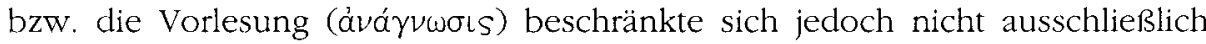
auf den engeren liturgischen Bereich ${ }^{18}$. Es finden sich hinreichend Indizien dafür, daß Heiligenviten in Klöstern auch außerhalb des Gottesdienstes und zu anderen Anlässen, hauptsächlich wohl zum Zwecke der seelischen Erbauung und Disziplinierung der Mönche, verlesen wurden (und werden ${ }^{19}$ ). Als gesichert darf in diesem Zusammenhang gelten, daß in Klöstern während der Mahlzeiten im Refektorium unter anderem auch Heiligenviten, vermutlich in Perikopen, verlesen wurden ${ }^{20}$. Den frühesten Beleg dafür bietet im betrachteten Zeitraum die Hypotyposis des Theodoros Studites ${ }^{21}$ vom Anfang des 9. Jahrhunderts, die aber in Einzelheiten sicher auf noch ältere Klostertypika, etwa aus Palästina, zurückgehen dürfte ${ }^{22}$. Dort wird in cap. 28 festgelegt, daß, nachdem die Brüder mit ei-

14 Vita Euthymii Sard. (BHG 2145) cap. 1, p. 21,10f

15 Vita Stephani iun. (BHG 1666) cap. 2, p. 90,23

16 Vgl dazu Vryonis, Panegyris 196-228; Calendine, Theosis 93

17 Vgl. noch Vita Niceph. Medic. (BHG 2297) cap. 4,6, p. 405: ákpoatás; Vita Theodori Edess (BHG 1744) cap. 1, p. 2: ákpoaraí. Vgl dazu auch Calendine, Theosis 58-65. 74: „oral literature"; McGrath, Life 92 Anm. 30. - Man könnte einwenden, daß auch die Erwähnung der Zuhörer in den Viten Topik sei. Das mag zutreffen, generell basiert dieser Topos aber auf dem situativen Kontext der Verlesung der Vita, von dem grundsätzlich ausgegangen werden konnte, anderenfalls wäre der Topos unpassend und hätte kaum Verbreitung gefunden.

18 Vgl. Onasch, Ostkirche 245-249 s. vv. „Lesebücher - Lesungen“; 267-269 s. vv. „Menaion - Menologion“; Høgel, Symeon 36-51; Franklin, Latin Dossier 153; Krueger, Writing 63-75.

19 Vgl. unten S. 375 Anm, 24, auch in westlichen Klöstern heute noch üblich.

20 Zur Verlesung in Abschnitten vgl. auch Talbot, Faith Healing 124 (Kommentar zu 44,5-6); Franklin, Latin Dossier 153. Vgl. Rapp, Figures 315; G. Makris, Kalendergedichte: Eine literarische Manifestation des byzantinischen Kirchenjahres, in: Der Kalender. Aspekte einer Ge schichte. Hrsg. von W. Geerlings, Paderborn-München-Wien-Zürich 2002, 146

21 Zu ihm vgl, Pratsch, Theodoros passim

22 Vgl. Meyer, Haupturkunden 15-20. Auch die Regula des Benedikt von Nursia (6. Jh.) und andere frühe Vorschriften im westlichen Mönchtum ordnen die Lesung der "Viten der Väter" an, vgl. Rapp. Hagiography 1279 . 
nem Vers im Mund den Speisesaal betreten und in schönster Ordnung und ohne Lärm auf Anweisung des Taxiarchen bei Tische Platz genommen haben, die Lesung stattfindet, die erst auf ein akustisches Signal hin mit dem letzten Gang der Mahlzeit endet ${ }^{23}$. Diese Regelung wurde unter anderem im 10. Jahrhundert von Athanasios vom Athos in seine Klosterordnung für die Laura übernommen ${ }^{24}$, dürfte aber aufgrund der großen Wirkung und Strahlkraft der studitischen Klosterordnung in den östlichen Kirchen eine weitaus größere Verbreitung gefunden haben ${ }^{25}$.

Weiterhin werden in der Hypotyposis des Theodoros Studites allenthalben Lesungen erwähnt, in den allermeisten Fällen ohne nähere Angabe des Inhalts $^{26}$. Daß es sich bei den zur Vorlesung kommenden Texten jedoch nicht ausschließlich um biblische Texte gehandelt hat, zeigen zwei Stellen der Hypotyposis recht deutlich: In cap. 16 wird festgelegt (wohl nicht durch Theodoros selbst, sondern durch seine Nachfolger), daß am Mittwoch und Freitag der Karwoche sowie am Ostersonntag jeweils aus den Katechesen „unseres Vaters Theodoros" vorgelesen wird" 27 . Und in cap. 21 wird bestimmt, daß während der heiligen Osterzeit in nahezu allen Abendgottesdiensten entweder vom Abt oder von einem der angesehenen und in der Redekunst erfahrenen Brüder den Mön-

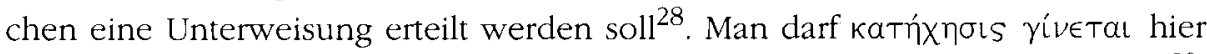
wohl so verstehen, daß jeweils eine vorgefertigte Katechese verlesen wurde ${ }^{29}$. Vor diesem Hintergrund erscheint die Annahme naheliegend, daß bei den zahl-

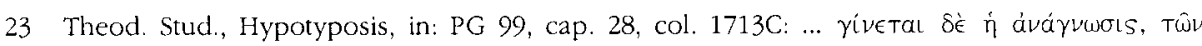

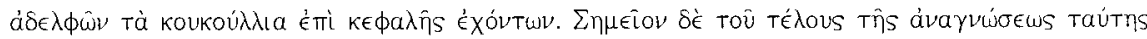

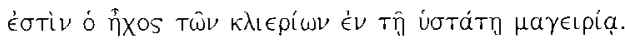

24 Vgl. Athanas. Athon., Hypotyposis, in: Meyer, Haupturkunden 136; bestätigt auch von der Vita

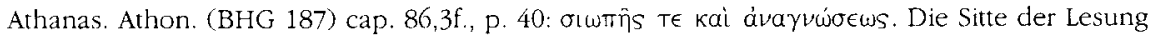
bei den gemeinsamen Mahlzeiten im Refektorium läßt sich auch heute noch in den Athosklöstern beobachten. Sie dient nicht allein der Erbauung, sondern unterbindet auch unerwünschte Gespräche der Mönche bei Tisch. Als akustische Signale dienen dabei ein Gong zur Hälfte der Lesung und Mahlzeit sowie ein weiterer Gong am Ende der Lesung und Mahlzeit.

25 Vgl. Meyer, Haupturkunden 15-20.

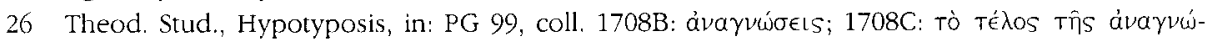

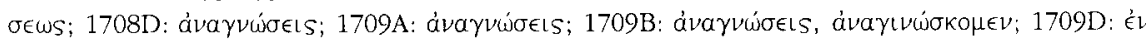

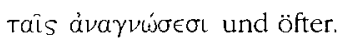

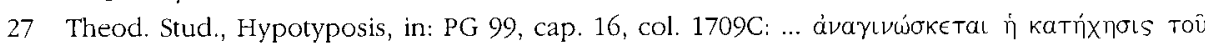

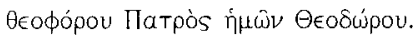

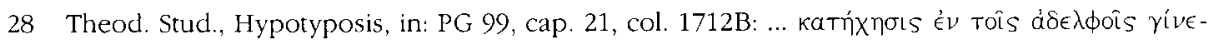
Tal.

29 Daß die Katechesen schriftlich fixiert wurden, zeigt ja Theodoros' eigene Hinterlassenschaft an diesen Stücken, vgl. dazu am besten Fatouros, Theodoros 21*-25*; PMBZ, Prolegomena $148 \mathrm{f}$. Vgl auch Pratsch, Kommunikationswesen (im Druck). 
reichen Lesungen im Studioskloster auch Heiligenviten zu Gehör gebracht wurden.

Schließlich kennt die Hypotyposis des Theodoros Studites aber auch stille Lesungen durch die Mönche in der Bibliothek: In cap. 26 wird nämlich festgelegt, daß an den Ruhetagen, an denen keine körperliche Arbeit verrichtet wird, die Brüder sich auf ein Zeichen des Bibliophylax hin in der Bibliothek versammeln. Ein jeder erhält dort ein Buch und liest bis zum Nachmittag ( $\lambda \alpha \mu \beta a ́ v \in 1$

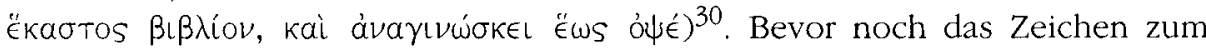
Vespergottesdienst ertönt, gibt der Bibliophylax erneut ein Zeichen, woraufhin alle ihre Bücher wieder abgeben. Wer sich bei der Abgabe der Bücher verspätet, soll bestraft werden ${ }^{31}$.

Es läßt sich anhand dieser Indizien also feststellen, daß zu der bereits von Ehrhard konstatierten liturgischen Verwendung der Heiligenviten noch eine katechetische Verwendung in den Klöstern trat. Für die letztere Verwendung kommen mit einiger Wahrscheinlichkeit auch etliche der sogenannten nichtmenologischen Sammlungen in Frage ${ }^{32}$.

Die literarische Gattung der Heiligenviten ist also im Kern eine zweckgebundene Literatur, die im wesentlichen dem liturgisch-katechetischen Gebrauch durch Mönchtum und Klerus diente. Wenn dem so ist, liegt es nahe, daß auch die Entstehung und Tradition dieser Literatur im wesentlichen den Mönchen und Klerikern oblag. Dies wird durch den überlieferten handschriftlichen Bestand bestätigt ${ }^{33}$. Wir können folglich konstatieren, daß die überwiegende Zahl der byzantinischen Heiligenviten für einen liturgisch-katechetischen Gebrauch bestimmt war und in einem monastisch-klerikalen Umfeld entstand ${ }^{34}$.

30 Dies läßt darauf schließen, daß etwa im ersten Viertel des 9. Jh.s in den Klöstern der studitischen Kongregation unter Theodoros Studites $(† 826)$ jeder oder fast jeder Mönch lesen konnte!

31 Theod. Stud., Hypotyposis, in: PG 99, cap. 26, col. 1713A-B.

32 Vgl. Ehrhard, Überlieferung III, 725-727. Ehrhard glaubte aus dem im Unterschied zu den menologischen Sammlungen (Quart- und Großquartformat) kleineren Format (Oktavformat) sowie ihrer geringen Eignung für die liturgischen Verwendung (nicht nach dem Kirchenkalender, sondern nach anderen Gesichtspunkten geordnet) schließen zu können, daß die nichtmenologischen Sammlungen für die "Pivatlektüre" bestimmt gewesen seien, er spricht an dieser Stelle von "Privatgebrauch" und "Privatsammlungen". Was genau Ehrhard dabei im Sinn hatte, wage ich nicht zu entscheiden. In jedem Fall scheinen auch die nichtmenologischen Sammlungen für einen katechetischen Gebrauch durchaus geeignet. Rapp, Figures 315f., bezeichnet in ihrer Studie, in der sie gerade nichtmenologische Sammlungen (Materika) untersucht, die individuellen Lesungen durch Nonnen im Kloster als "private readings“. Diese Art der Lesung könnte man ebenfalls als katechetisch bezeichnen.

33 Vgl. Ehrhard, Überlieferung passim. Trotz mancher Unsicherheiten, was die Provenienz einzelner erhaltener Hss. angeht, läßt sich doch erkennen, daß der Kernbestand der hagiographischen Hss. der monastisch-klerikalen Tradition entstammt. Vgl. auch Ehrhard, Überlieferung I, VIIf.; III, 968 und öfter. 
Der so definierte Regelfall der Entstehung einer Heiligenvita verhinderte selbstverständlich nicht, daß es zum einen von vornherein, zum anderen vor allem im weiteren Verlauf der Entwicklung dieser Literatur und im Zuge ihrer literarischen Adaption und Mimesis, immer wieder zu Abweichungen von dieser Regel kam. So lassen sich etwa isolierte (sogar familiäre) Kultbegründungen greifen, ebenso dienten einzelne Viten dem Zweck der Privilegiensicherung oder der ideologischen Rechtfertigung, andere, auch fiktive und halbfiktive, Stücke kursierten als Erbauungsliteratur in Laienkreisen. Diese Vertreter der hagiographischen Literatur müssen jedoch als Ausnahmen begriffen werden; als Argument gegen die Regel haben sie kein Gewicht.

\section{B. Die einzelne Heiligenvita}

Eine andere Fragestellung ist die nach der Entstehung einer einzelnen, individuellen Heiligenvita. Wenn die Heiligenvita nicht direkt für eine Sammlung geschrieben wurde, was bei Viten späterer Heiliger durchaus denkbar erscheint, zielt diese Frage auf den Zeitraum, der noch vor dem Zeitpunkt der Aufnahme der Vita in eine Sammlung lag ${ }^{35}$.

Die genaue Art und Weise, in der eine einzelne Heiligenvita entstand, läßt sich in den Texten selbst kaum greifen und nur in recht wenigen Fällen aufgrund verschiedener Indizien einigermaßen plausibel rekonstruieren. Erschwerend kommt hinzu, daß die ohnehin spärlichen Angaben, die die Hagiographen hin und wieder zu dieser Frage machen, etwa die Abfassungszeit betreffend, in nicht wenigen Fällen einem propagandistischen Zweck unterliegen und bewußt irreführend $\operatorname{sind}^{36}$.

Wenn also keine genaueren Angaben gemacht werden oder diese zweifelhaft sind, geht man deshalb in der Forschung im allgemeinen von einem vermeintlich naheliegenden und wahrscheinlichen Normalfall aus, auf den sich auch durchaus Hinweise in verschiedenen Viten finden. Dieser Normalfall wird gewöhnlich in etwa so beschrieben, daß „einige Zeit nach dem Tod des Heiligen einer der Mönche des Klosters bzw. ein Schüler des Heiligen aus eigenem Antrieb oder auf Geheiß des Abts bzw. des Bischofs ${ }^{37}$ eine Vita des Heiligen niederschrieb".

Diese gängige Vorstellung enthält auf der einen Seite noch eine ganze Reihe von variablen Größen: „Einige Zeit nach dem Tod des Heiligen“ kann wohl ei-

35 Vgl. dazu Ehrhard, Überlieferung I, 19 Anm. 3; III, 942-967; Høgel, Symeon 36.

36 Vgl, Dobschütz, Methodios bes. 54f.; Pratsch, Fact and Fiction 64-66.

37 Vgl. dazu oben Erster Teil, Kap. 1: „Prooimia“, zum Auftragstopos, S. 26-28. 
nen zeitlichen Abstand von nur wenigen Tagen und Wochen bis hin zu Jahrzehnten oder gar Jahrhunderten bezeichnen. Es steht lediglich fest, daß die Vita im allgemeinen post mortem verfaßt wurde. Auch im Hinblick auf den Verfasser, „einen der Mönche bzw. Schüler“, bleibt einiger Spielraum für Interpretation. Welchen genauen Status hatte der Hagiograph im Einzelfall, in welchem persönlichen Verhältnis stand er jeweils zu dem Heiligen? Schließlich sagt auch die Feststellung, daß der Verfasser „eine Vita des Heiligen niederschrieb“, nichts über die genaue Art und Weise dieses Vorgangs aus. Nach der communis opinio impliziert diese Vorstellung zwar eine bestimmte, gewissermaßen idealtypische Entstehungsweise (nämlich daß die Vita nur wenige Jahre nach dem Tod des Heiligen von einem direkten Schüler desselben in einem Stück niedergeschrieben wurde) - genau genommen läßt sie aber viele Fragen offen.

Der Frage nach der Entstehung einer einzelnen Heiligenvita wurde bisher in der byzantinistischen Forschung kaum Aufmerksamkeit gewidmet, so daß die Genese einer byzantinischen Heiligenvita noch immer ein eigenes, bisher nur unzureichend erforschtes Gebiet innerhalb der byzantinischen Hagiologie darstellt. Es lassen sich jedoch verschiedene, spezifische Wege der Entstehung einer Heiligenvita erkennen und beschreiben, von denen vor allem die Wege der schrittweisen Entstehung einer Heiligenvita aus anderen literarischen Formen von besonderem Interesse sein dürften ${ }^{38}$. Hier ist nicht der Raum, um die vielfältigen Formen der Entstehung erschöpfend behandeln zu können, dennoch soll einiges zumindest kurz umrissen werden:

\section{Entstehung als Epitaphios}

Für eine Reihe von Viten steht außer Zweifel und läßt sich nachweisen, daß der überlieferten Vita eine tatsächliche Grabrede (Epitaphios Logos) auf den Heiligen zugrundelag ${ }^{39}$. Dies zeigt sich im überlieferten Bestand zunächst darin, daß eine methodisch saubere Unterscheidung zwischen einer Heiligenvita und einer Grabrede auf einen Geistlichen in unserer Zeit nicht einwandfrei möglich ist. Auch wenn der Epitaphios als eigene Gattung anhand einzelner Beispiele deut-

38 Etliche Viten entstanden anscheinend eben gerade nicht "in einem Stück", sondern in mehreren, auch zeitlich auseinanderliegenden Schritten der Überarbeitung und Weiterentwicklung eines ursprünglich kürzeren Textes. Vgl. dazu auch McGrath, Life 89. 102 Anm. 52; Høgel, Symeon 20: "hagiographical texts tend to develop gradually, from copy to copy“.

39 Vgl. Vita Mariae iun. (BHG 1164) cap. 11, p. 697A-B: Grabrede des Oikonomos Anthimos anläßlich der Beisetzung der Maria in Bizye in Thrakien im Jahre 903, s. dazu oben S. 337 Anm. 87. - Vgl. auch S. Efthymiadis, in: Vita Tarasii (BHG 1698) S. 47: zur Vita Nicephori patriarchae (BHG 1335). 
lich zu erkennen ist ${ }^{40}$, so gibt es doch zahlreiche Berührungspunkte und einen fließenden Übergang von einem Genre zum anderen: Einige der gemeinhin als Epitaphioi gehandelten Texte unterscheiden sich kaum von einer typischen Heiligenvita ${ }^{41}$, und umgekehrt weisen sich einige der üblicherweise als Heiligenviten angesehenen Texte in ihrer Überschrift als Epitaphios aus ${ }^{42}$. Verschiedene rhetorische Elemente des Threnos, wie sie für den Epitaphios als typisch gel$\operatorname{ten}^{43}$, finden sich ebenso in einer ganzen Reihe von Heiligenviten ${ }^{44}$.

Zwei Beispiele für diese Art der Entstehung, gewissermaßen zwei unvollendete Zwischenschritte auf dem Weg vom Epitaphios zur Vita, wären etwa die beiden Epitaphioi des Theodoros Studites auf seine Mutter (BHG 2422) und auf seinen Onkel Platon (BHG 1553). Von diesen beiden ist der Epitaphios auf seine

$40 \mathrm{Vgl}$ als ein typisches Beispiel die Grabrede des Eustathios von Thessalonike auf den Metropoliten von Athen, Nikolaos Hagiotheodorites, ed. A. Sideras, in: Grabreden 31-50; auch die Leichenrede des Theodoros Studites auf seine Mutter (BHG 2422), in: PG 99, 884-901, darf man noch zu den „echten“ Epitaphioi zählen; vgl. im übrigen Sideras, Grabreden passim, wo sich auch zeigt. daß reine Epitaphioi in unserer Zeit (6,-10. Jh.) dünn gesät sind und in größerer Zahl aus späterer Zeit erhalten sind; oft handelt es sich dabei um Grabreden auf höhere Würdenträger und Angehörige des Kaiserhauses.

41 Beispielsweise der Epitaphios des Petros von Argos auf Athanasios von Methone, vgl. PMBZ, Prolegomena 119f.; Sideras, Grabreden 104-107, oder, deutlicher noch, der Epitaphios des Theodoros Studites auf seinen Onkel Platon, vgl. PMBZ, Prolegomena 72f:; Sideras, Grabreden 97-99.

42 So könnte beispielsweise die Vita Nicet. Medic. (BHG 1341) mit gleichem Recht auch als Epitaphios des Theosteriktos auf Niketas von Medikion bezeichnet werden, vgl. die Überschrift:

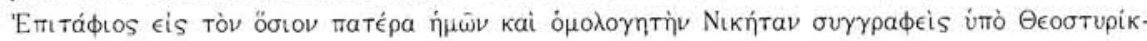

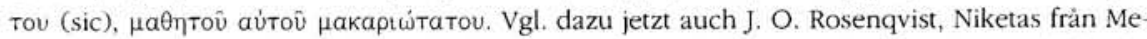
dikion, bara nästan en hjälte för ikonerna (Niketas von Medikion, nur zum Teil ein Held für die Bilder), in: Bysantinska Sällskapet, Bulletin 16 (1998) 11-16, der darauf besteht, daß es sich um einen Epitaphios handelt; von A. Sideras dagegen wurde der Epitaphios des Theosteriktos auf Niketas von Medikion in seiner Spezialuntersuchung nicht berücksichtigt, vgl. Sideras, Grabreden 7 (Inhalt), wohl eben weil er in der Forschung meistens zu den Heiligenviten gerechnet wird. In dieser Frage ist wohl eher Sideras Recht zu geben, da der Text ein ganz wesentliches Element der Viten aufweist, das auch zur Unterscheidung von Epitaphios und Vita herangezogen werden kann, nämlich die Wunder, vgl. Vita Nicet. Medic. (BHG 1341) cap. 44, p. XXVIf. (Gefangenenbefreiung); cap. 45, p. XXVII (Errettung aus Schiffbruch); cap. 48f., p. XXVII (Dämonenaustreibung, Heilungen von Krankheiten, darunter Blutfluß). Allerdings werden einige der Wunder so stichwortartig angeführt, daß sich der Gedanke aufdrängt, daß die uns vorliegende Fassung der Vita nicht die "vollständig umgearbeitete" Fassung sein kann. Vgl. jetzt aber Rosenqvist, Niketas 59-72.

43 Vgl. Sideras, Grabreden 78.

44 So findet sich beispielsweise die nach Sideras, Grabreden 82, typische, „angeblich durch die Intensität der Trauer verursachte Verwirrung des Redners" auch im Proöm der Vita Nicephori patriarchae (BHG 1335) des Ignatios Diakonos; s. dazu bereits oben S. 24. Zahlreiche weitere Beispiele ließen sich hier beibringen. 
Mutter schmuckloser und weist ein recht eigenartiges (wenig rhetorisches) Proöm auf, während der Epitaphios auf Platon über ein ordentliches (rhetorisches) Proöm verfügt und im Grunde eine vollständige Heiligenvita darstellt, welcher nur noch die unabdingbaren Wunder fehlen.

In vielen Fällen scheinen ursprüngliche Epitaphioi anschließend, vermutlich im Zuge der Entwicklung des Kults des jeweiligen Heiligen, zu vollständigen Heiligenviten ausgearbeitet worden zu sein. Spuren dieser Ausarbeitung lassen sich in den Viten bisweilen noch erkennen. Einige Beispiele sollen dies illustrieren:

Die ältere Vita des Styliten Alypios (BHG 65) weist sich von Anfang an als

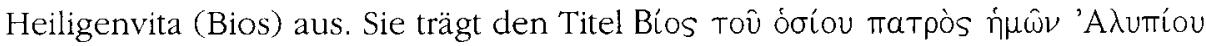

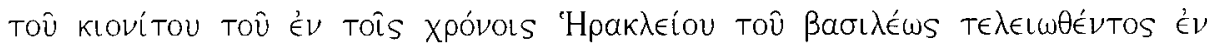

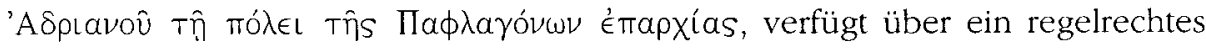
Proöm und enthält auch sonst sämtliche Elemente einer Heiligenvita einschließlich der Wunder. Es findet sich jedoch eine Stelle, wo der Verfasser expressis verbis feststellt, daß er seinem heiligen Vater einen "Epitaphios Logos" darbringt ${ }^{45}$ : „Und ich nun, der sehr unbedeutende und späte Nebenschößling ${ }^{46}$ deiner Pflanzung, Vater, erkühnte mich, dir diese Leichenrede darzubringen, ..."

Es dürfte sich daher bei der Vita des Alypios ursprünglich um einen Epitaphios Logos gehandelt haben. Eine Erklärung des Problems könnte folgendermaßen aussehen: Die ursprüngliche Leichenrede wurde nur einmal gehalten, nämlich in der Regel anläßlich der Beisetzung, vielleicht auch bisweilen anläßlich der ersten Wiederkehr des Todestages (bezeichnet als dies natalis) des Heiligen. Sie wurde dann später, wohl zum Zwecke der regelmäßigen Verwendung in den Gedenkgottesdiensten am alljährlich wiederkehrenden Festtag des Heiligen (Panegyris) ${ }^{47}$, zu einer Heiligenvita umgearbeitet. Bei dieser Umarbeitung übersah man anscheinend die angeführte Stelle oder hielt ihre Änderung nicht für erforderlich. Sie kann daher als ein Indiz dafür dienen, daß in diesem Falle eine Überarbeitung eines Epitaphios Logos zu einer Heiligenvita erfolgte ${ }^{48}$.

In der Vita des Theodoros Studites (BHG 1754) erzählt der Verfasser, der Mönch Michael, vergleichsweise stringent und chronologisch die Lebensgeschichte des Theodoros. An einer bestimmten Stelle (nämlich im Jahre 821 in Lakku Mitata in Bithynien ${ }^{49}$ ) angekommen, bemerkt der Verfasser plötzlich ${ }^{50}$ :

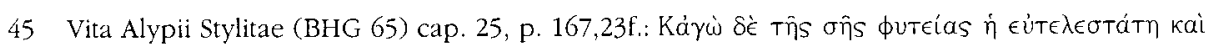

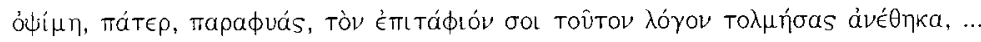

46 Der Verfasser stellt sich also nicht als einen älteren und vertrauten, sondern als einen jüngeren und weniger vertrauten Schüler des Heiligen dar (Bescheidenheitstopos).

47 Vgl. dazu Vryonis, Panegyris 196-228; Calendine, Theosis 93

48 Vgl. auch Delehaye, Stylites LXXVIIf.

49 Vgl. Pratsch, Theodoros 264 
„Daselbst nun soll unser göttlicher Vater auch Wunder getan haben, die es nicht verdient haben, dem Vergessen anheimzufallen ${ }^{51}$, auf die ich nun mit Gottes Hilfe in angemessener Weise versuchen will, die Rede zu lenken." Es folgt dann über etliche Kapitel (capp. 48-57) eine Sammlung der verschiedensten Wunder des Theodoros, auch der postumen, die mit den Ereignissen in Lakku Mitata nicht das geringste zu tun haben. Schließlich wird in cap. 59 die Erzählung der Lebensgeschichte des Theodoros mit den Ereignissen in Bithynien im Jahre 821 wieder aufgenommen und fortgesetzt. Es entsteht folglich der Eindruck, daß die Wunder des Theodoros an dieser Stelle in den Text der Vita, die ursprünglich nur die Lebensgeschichte des Theodoros berichtete, später eingefügt wurden ${ }^{52}$ Es ist daher denkbar, daß die Vita des Theodoros auf einem ursprünglichen Epitaphios Logos basiert, der später in der Überarbeitung des Michael Monachos zu einer vollständigen Heiligenvita ausgearbeitet wurde.

Das Proöm der als Epitaphios betitelten Vita des Niketas von Medikion (BHG 1341) beginnt sehr ungewöhnlich ${ }^{53}$, indem gleich im ersten Satz der Name des Heiligen genannt wird und im Anschluß der Verfasser Theosteriktos sich selbst als Schüler des Heiligen vorstellt. Eine solche Eröffnung paßt in der Tat gut zum Vortrag eines Epitaphios; sie paßt jedoch nicht in das übliche Schema der Proimia der Heiligenviten. Im folgenden entspricht das Proöm der Vita dann allerdings durchaus dem üblichen rhetorischen Muster. Es könnte daher möglich sein, daß es sich bei der Überschrift und der Eröffnung des Proöms um die Überschrift und Eröffnung des ursprünglichen Epitaphios handelt, während das übrige Proöm vielleicht erst später ausgearbeitet wurde. Der Anfang der Vita des Niketas von Medikion wäre somit möglicherweise als eine Zwischenstufe oder Übergangsform auf dem Wege vom Epitaphios zur Heiligenvita zu betrachten ${ }^{54}$.

Es kann also als erwiesen gelten, daß ein Weg der Entstehung einer einzelnen Heiligenvita in der späteren Überarbeitung und Elaboration einer früheren

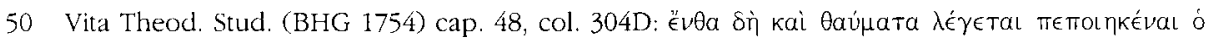

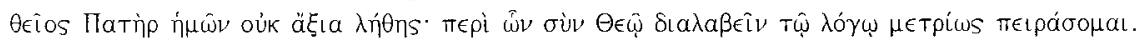

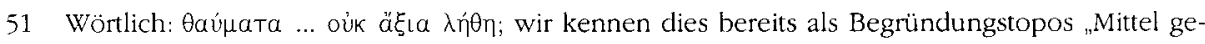
gen das Vergessen" (oblivionis remedium) des Proöms, der hier, eingangs der Wundersammlung, aber ebenfalls gebracht wird.

52 Es läßt sich dabei nicht sagen, ob die Wunder zunächst separat gesammelt worden waren und en bloc an dieser Stelle eingefügt wurden, oder ob zunächst nur eines oder einige Wunder an dieser Stelle eingefügt wurden und weitere dann später hinzukamen; cf. dazu auch PMBZ, Prolegomena $75 \mathrm{f}$.

53 Vita Nicet. Medic. (BHG 1341) cap. 1, p. XVIII.

54 Der Chrakter dieser Vita als Übergangsform vom Epitaphios zur Vita zeigt sich auch anhand anderer Indizien wie etwa der Überschrift und der in der Vita berichteten Wunder, s. dazu bereits oben S. 379 Anm. 42. 
Grabrede (Epitaphios Logos) auf den Heiligen bestand. Dem ehemaligen Epitaphios wurden zu einem späteren Zeitpunkt weitere literarische Elemente hinzugefügt, vor allem ein ordentliches Proöm und die notwendigen Wunder, und er wurde möglicherweise auch stilistisch überarbeitet, so daß aus dem Epitaphios eine vollgültige Heiligenvita entstand. Akzeptiert man die Elaboration eines Epitaphios zu einer Heiligenvita, muß man gleichzeitig auch die schrittweise Entstehung einer einzelnen Heiligenvita anerkennen. Als Ausgangspunkt einer solchen schrittweisen Genese diente jedoch nicht nur die Grabrede, sondern auch verschiedene andere literarische Formen:

\section{Entstehung als Katechese}

Unter den zahlreichen Katechesen des Studitenabts Theodoros findet sich auch eine, in der eines unlängst verstorbenen Bruders ${ }^{55}$ gedacht wird. Im Rahmen dieses Gedenkens findet sich in dieser Katechese auch ein kurzer Abriß des Lebens des frommen Mönchs, welcher folgendermaßen lautet ${ }^{56}:$ „Weil jetzt auch ein würdiger Greis entschlafen ist, ist es nötig, etwas in wenigen Worten zum gemeinsamen Nutzen über ihn zu sagen. Daß er nun von frühester Jugend an bis ins höchste Alter Gott diente, indem er das Leben eines Mönchs führte, ist dem Greis bereits hinreichendes Lob, ferner daß der Mann ein Bekenner war und von dem gottlosen Leon ergriffen und schwer bestraft wurde. Mit dreißig Peitschenhieben nämlich zerschnitten sie ihm den Rücken und die Brust, und mit Faustschlägen und Backenstreichen zerschlugen sie ihm das Gesicht, so daß ihm auch zwei der Zähne herausbrachen. Dann, so nach einigen Jahren, führte er (sc. der Kaiser) ihn aus dem Gefängnis und ließ ihn frei. Der (sc. Mönch) nun kehrte zu seinem früheren Leben zurück, denn er war auch Stylit, und schloß sich wieder in seine Zelle ein. Dort verbrachte er in großer Geduld und Entbehrung die letzte Zeit seines Lebens und übergab seine Seele dem Herrn. Der

55 Vgl. PMBZ: \# 11371

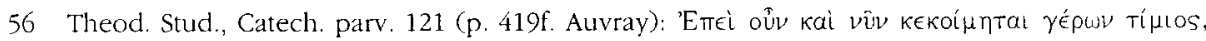
áva

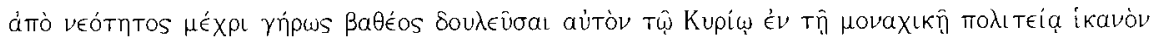

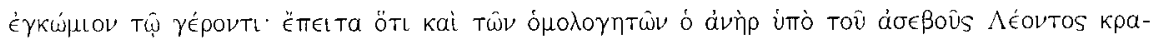

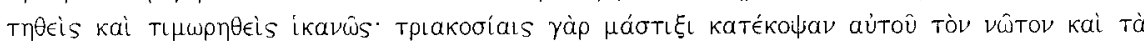

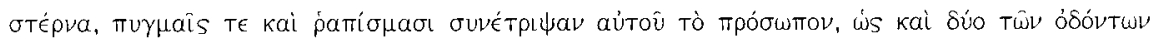

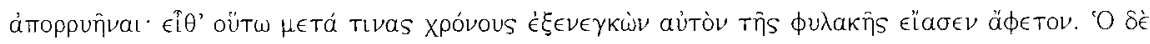

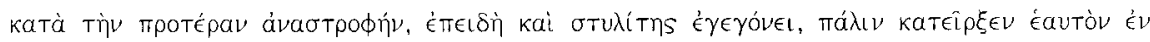

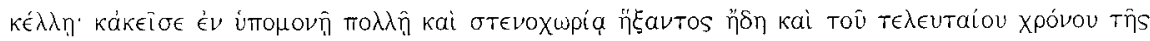

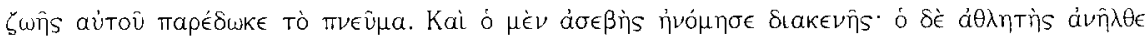

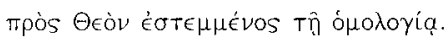


Gottlose (sc. der Kaiser) nun handelte vergebens gegen das Gesetz, der Kämpfer (sc. der Mönch) aber ging ein zum Herrn gekrönt mit dem Bekenntnis."

Diese Darstellung des Lebens des unbekannten Mönchs kann guten Gewissens als eine Vita in nuce bzw. als eine Kurzvita betrachtet werden ${ }^{57}$. Wir wissen nicht, ob Theodoros Studites in seiner Katechese vielleicht in der Tat die künftige Vita eines ikonodulen studitischen Bekenners im Keim anlegen wollte Auf den ersten Blick ist dies nicht sehr wahrscheinlich, da man erwarten würde, daß er dann zumindest auch den Namen des Mönchs vor dem Vergessen bewahrt haben würde. Andererseits wußte sein Auditorium natürlich genau, von wem hier die Rede war. Man kann sich jedenfalls sehr gut vorstellen, daß dieses Stück aus der Katechese exkorporiert und schrittweise zu einer vollständigen Heiligenvita ausgearbeitet werden konnte. Das Beispiel zeigt also, daß auch in einer Katechese jener hagiographische Kern angelegt sein konnte, aus dem sich eine Heiligenvita entwickeln ließ.

\section{Entstehung als Mneme bzw. Kurzvita}

Die kürzeste Form der Mneme $(\mu \nu \eta \dot{\eta} \eta)^{58}$, der Erwähnung des Gedenkens eines bestimmten Heiligen zu Ehren seines Todestages (dies natalis) in den Menolo-

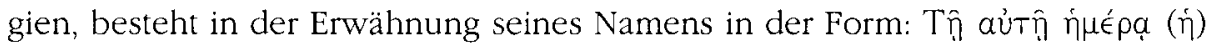

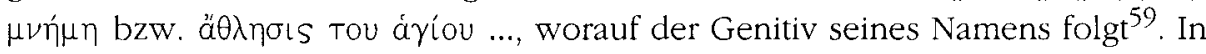
vielen Fällen wurde diese schlichteste Form der Mneme jedoch, wohl jeweils abhängig von der Entwicklung des Kultes und der damit verbundenen Bedeutung des Heiligen, um eine kurze Lebensskizze des Heiligen erweitert. Bei diesen kurzen Lebensskizzen handelt es sich um die sogenannten Kurzviten in den Synaxaren bzw. Menologien ${ }^{60}$.

Es läßt sich nun zeigen, daß im Verlaufe der Vervielfältigung und Tradierung der Synaxar- bzw. Menologien-Hss auch diese kurzen Lebensskizzen bzw. Kurzviten zusätzliche Erweiterungen in Richtung einer vollgültigen Heiligenvita erfuhren ${ }^{61}$. Ein Beispiel soll dies hier exemplifizieren:

Im Synaxar von Konstantinopel ${ }^{62}$ finden sich zwei Versionen der Kurzvita eines Theophilos aus Tiberiupolis in Thrakien (BHG 2450). Die frühere ${ }^{63}$ und

57 Inhaltlich gesehen ist das Stück ein stark verknappter Epitaphios, der hier in die Form einer Katechese integriert wurde.

58 Vgl. auch ThWbNT 4 (1942) 678-687.

59 Vgl. etwat Synax. Cpl. 543,1. 544,25. 546,9.548,19 et ubique; Men. Basilii 200C. 201B. 204A 209A-B et ubique.

60 Diese Kurzviten wurden als Gegenstand dieser Arbeit im wesentlichen ausgeklammert, siehe oben S. 9-11. 
kürzere Version I (Synax. Cpl. 100,8-35) stellt eine Synaxarnotiz (eines ikonodulen Bekenners) im herkömmlichen Sinne dar und beschränkt sich auf das wesentliche, nämlich den Namen und die Herkunft des Heiligen, seinen Eintritt in den Mönchsstand, seine Frömmigkeit, Verhör durch den Kaiser, Bestrafung mit Verbannung und schließlich körperliche Züchtigung. Die spätere ${ }^{64}$ und längere Version II (Synax. Cpl. 125/26,41 - 129/130,46) hat nicht nur rein quantitativ den Umfang des Textes etwa auf das Vierfache erweitert, sie hat auch zahlreiche weitere hagiographische Topoi, narrative Elemente und erste Wunder aufgenommen, die dem Ganzen eine völlig neue Qualität verleihen. Es entsteht dabei der Eindruck, daß die beiden Versionen der Kurzvita des Theophilos zwei Stufen einer Entwicklung repräsentieren, nämlich der Entstehung einer vollgültigen Heiligenvita aus einer Synaxarnotiz bzw. Kurzvita. Dabei stellt Version I als Kurzvita sozusagen die spätere Vita in nuce dar, während Version II mit ihren zahl- und umfangreichen Erweiterungen bereits einen entscheidenden Schritt in Richtung einer "vollständigen" Heiligenvita unternommen hat, ohne freilich das Endstadium dieser Entwicklung erreicht zu haben ${ }^{65}$. Dieses Beispiel macht die schrittweise Elaboration einer Heiligenvita aus einer früheren Synaxarnotiz bzw. Kurzvita wahrscheinlich ${ }^{66}$.

61 Die Bollandisten, die sich als erste und am ausführlichsten mit der Synaxarliteratur beschäftigten, vertraten die Ansicht, daß die Kurzviten, aus denen die Synaxare im wesentlichen bestehen, Kurzfassungen bzw. Exzerpte längerer Heiligenviten seien, daß diese also „e documentis prolixioribus contracta esse" (wie Hippolyte Delehaye es bereits 1902 formulierte, in: Synax Cpl. LIX), es sich dabei also um „éloges abrégés des saints" handele (wie Jaques Noret es ausdrückte: AnBoll 86 [1968] 21). Von dieser Regel scheint es zumindest Ausnahmen zu geben, denn in Einzelfällen liegt offenbar die umgekehrte Entwicklung vor.

62 Synax Cpl. 100,8-35 und 125/26,41 - 129/130,46. Zum 2. und 10. Oktober.

63 Version I (Siglum 5 Delehaye) stammt aus dem codex (Sirmondianus) Berolinensis graecus 219 , dessen in Frage kommender Abschnitt (folia 13-300 [Pergament]) in das 12./13. Jh. datiert wird (folia 1-12 [Papier]: saec. XV). Die Hs. führte verschiedene Bezeichnungen: synaxarium Claromontanum (nach dem Ort des Kollegs der Societas Jesu in Clermont in Paris), Sirmondianum (nach dem Bibliothekar des Kollegs, Pater Jacques Sirmond), collegii societatis Jesu Parisiensis (nach dem Kolleg), collegii Ludovici Magni; mit dem gesamten Besitz des Kollegs von Clermont gelangte die Hs. dann in die Bibliothek von Meerman und später in den Besitz von Sir Thomas Phillips; schließlich erwarb die königlich-preußische Bibliothek zu Berlin den ehemaligen Besitz von Meerman, so daß die Hs. nach Berlin kam. Demnach führte die Hs. verschiedene Katalogbezeichnungen: cod. Claromontanus 209. Meermannianus 372, Phillippicus 1622 und schließlich cod. bibliothecae regiae Berolinensis graecus 219. - Dies ist die ursprünglichste Fassung, die Delehaye auch zur Grundlage seiner Textkonstitution des Synaxars von Konstantinopel nahm, vgl. H. Delehaye, in: AnBoll 14 (1895) 396 434; dens., in: Synax. Cpl. VI-LII.

64 Version II (Siglum M Delehaye) stammt aus dem codex Parisinus graecus 1582, der in das 14. Jahrhundert datiert wird. 


\section{Entstehung aus Viten anderer Heiliger}

Es sind eine ganze Reihe von Fällen bekannt, in denen im Rahmen einer herkömmlichen Heiligenvita eine weitere, kürzere Lebensgeschichte eines anderen Protagonisten bzw. Heiligen ${ }^{67}$ erzählt wird ${ }^{68}$. Ein Beispiel dafür wäre etwa die Lebensgeschichte des Nikolaos Stratiotes ${ }^{69}$, die in der Vita des Nikolaos Studites (BHG 1365) berichtet wird ${ }^{70}$ : Als junger Mann zog er im Range eines Scholarios unter Kaiser Nikephoros I. mit auf den Feldzug des Jahres 811 gegen die Bulgaren, blieb jedoch unterwegs in Thrakien zurück. Er wurde von einer wohlhabenden Frau freundlich aufgenommen und bewirtet. Als Nikolaos sich zum

65 Men. Basilii 84B-D (10. Oktober): bietet eine noch kürzere Version der Kurzvita, wo sogar der Herkunftsort des Theophilos fehlt. Diese Version muß jedoch hier unberücksichtigt bleiben und zwar aus folgenden Gründen: Bei der einzigen Hs. (Vat. gr. 1613) dieses Menologiums handelt es sich um eine illuminierte Prachthandschrift, in der sämtliche Kurzviten einen Umfang von 16 Zeilen pro Seite aufweisen, offenbar um genügend Raum für die Illustration zu lassen (430 Miniaturen, davon fehlt bei 15 Miniaturen der Text, bei 2 Miniaturen Text und Titel). Die Hs. ist datiert zw. 979 und 986 (vgl. S. Der Nersessian, in: Byz 15 [1940/41] 104-125) oder Anfang 11. Jh. (vgl. ODB 2, 1341f. s. v. „Menologium of Basil II") und könnte daher als Vorlage für die oben behandelte Version I des Synax. Cpl. gedient haben, aufgrund der Eigenheiten der Hs., eben des gleichförmigen Textumfanges der Kurzviten, läßt sich dies allerdings nicht mit Sicherheit sagen, und es muß offen bleiben, ob es sich dabei nicht doch bereits um eine gekürzte Fassung (etwa der Version I) handelt. Zum Men. Basilii vgl. noch unten S. 419f.

66 Der Beweis wäre durch einen stilistischen Vergleich zweier Versionen zu erbringen. Im vorliegenden Fall finden sich zwar lexikalische Übereinstimmungen, aber keine identischen längeren Formulierungen. Diese Frage sollte jedoch eingehender auf einer breiteren Materialbasis geklärt werden. - Der umgekehrte Weg, nämlich die Aufzeichnung von Mnemen und Synaxarnotizen nach einer Heiligenvita, ist häufiger dokumentiert: Christophoros Mitylenaios, Nikodemos Hagiorites (Hinweis G. Makris).

67 Der Status der Heiligkeit ist in diesen Fällen nicht immer so unstrittig wie in dem folgenden ersten Beispiel des Nikolaos Stratiotes, einige der Protagonisten haben anscheinend nie den Status vollgültiger Heiligkeit erlangt.

68 Vgl. auch M. Hinterberger, Autobiography and Hagiography in Byzantium, in: Symbolae Osloenses 75 (2000) 158, zu einer autobiographischen „Vita“ des Verfassers Antonios in der Vita des Georgios von Choziba (BHG 669). Vgl. auch Efthymiadis, Hagiographer and Audience 62. C. Rapp und andere Gelehrte betrachten diese integrierten Lebensgeschichten als „erbauliche

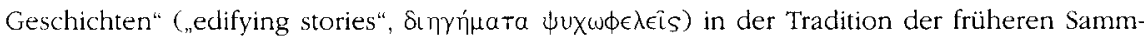
lungen wie der Apophtegmata Patrum und des Pratum Spirituale, vgl, auch A. Binggeli, Collections of Edifying Stories, in: S. Efthymiadis (ed.), Byzantine Hagiography: A Handbook, Alders hot 2006 (im Druck). Das muß hier nicht geklärt werden, denn für die These, daß aus diesen inkorporierten Lebensgeschichten vollständige Heiligenviten herausgearbeitet werden konnten, ist dies nicht relevant.

69 Vgl. C. Ludwig, in: PMBZ, Prolegomena 115f.; PMBZ: \# 5579.

70 Vita Nicolai Studitae (BHG 1365) 893B-897C; parallel erwähnt in Synax. Cpl. 341/342,21 - 343/ 344,35 (zum 24. Dezember) (= BHG 2311) 
Schlafen niedergelegt hatte, suchte ihn die Frau auf und wollte ihn verführen, er aber wies sie dreimal zurück und floh. Die verschmähte Frau war darüber so verärgert, daß sie ihren Dienern auftrug, ihn zu verfolgen und zu töten. Er entkam jedoch mit Gottes Hilfe. Später sah er in einem Traum die Niederlage der Byzantiner gegen die Bulgaren voraus. Er kam bei den Bergen in Bulgarien an und hatte dort eine Erscheinung, worin ihm ein Engel verkündete, daß der Herr ihn vor dem Tode gerettet habe, weil er seine Keuschheit bewahrt habe. Daraufhin wurde Nikolaos Mönch und später ein bedeutender Mönchsvater in Atroa. Als alter Mann erzählte er seine Erlebnisse dem Kyprianos, welcher sie dem Abt des Studiosklosters, Anatolios, weitererzählte, der die Niederschrift durch einen Mönch des Klosters anordnete. Es handelt sich also um eine kürzere Vita in nuce des Nikolaos Stratiotes, die im Rahmen der Vita des Nikolaos Studites (BHG 1365) überliefert wird. Daß die Lebensgeschichte des Nikolaos Stratiotes aber bereits eine gewisse hagiographische Eigenständigkeit besaß, sozusagen bereits ein hagiographisches Eigenleben begonnen hatte, zeigt sich insbesondere daran, daß sich eine etwas variierende Kurzvita des Nikolaos Stratiotes auch im Synaxar von Konstantinopel findet ${ }^{71}$.

In der Vita des Petros von Atroa (BHG 2364-2365) wird die Lebensgeschichte des Mönchs und Asketen Paulos (von Mantineion) erzählt ${ }^{72}$ : Paulos war seit seiner Kindheit Novize bzw. Mönch im Mantineionkloster ${ }^{73}$, wo er etliche Jahre lebte, bis einige Asketen den Abt des Mantineionklosters ${ }^{74}$ baten, daß ihnen Paulos als Diener übergeben werde. Der Abt gab seinen Segen, und Paulos wurde nun Diener der Asketen Eustratios ${ }^{75}$, Theodoros ${ }^{76}$ und Georgios $^{77}$ in der Nähe des Mantineionklosters. Die Asketen unterwiesen ihn in der Hesychia $^{78}$, er ging dann nach Krypta in Phrygien und lebte dort als Asket. In Krypta begegnete ihm Theophylaktos, der spätere Petros von Atroa ${ }^{79}$, und wurde sein Jünger. Paulos weihte Theophylaktos zum Mönch und gab ihm den Mönchsnamen Petros. Als Paulos die Zeit der Priesterweihe des Petros für gekommen hielt, wohl im Jahre 803 oder wenig später, schickte er ihn mit einem

71 Vgl. Synax. Cpl. 341/342,21 - 343/344,35.

72 Vita Petri Atroënsis (BHG 2364) cap. 5-11, p. 77-97; Vita Petri Atroënsis retractata (BHG 2365) cap. $5-11$, p. $84-96$

73 Das Mantineionkloster lag vermutlich bei Prusias im Thema Bukellarion, cf. V. Laurent, in: Vita Petri Atroënsis (BHG 2364) 62 (carte).

74 Vgl. PMBZ: $\# 10985^{*}$.

75 Vgl. PMBZ: $\# 1815$.

76 Vgl. PMBZ: \# 7611.

77 Vgl. PMBZ: $\# 2184$.

78 Genauer gesagt, in einer besonderen Form der Askese, nämlich der „Xeniteia“, cf. dazu V. Lau rent, in: Vita Petri Atroënsis (BHG 2364) 79 Anm. 4.

79 Vgl. PMBZ: $\# 6022$. 
Brief zum Patriarchen von Konstantinopel, Tarasios ${ }^{80}$, welcher Petros mit einem patriarchalen Schreiben zurückschickte, das den Bischof Basileios von Zygos ${ }^{81}$ mit der Priesterweihe des Petros beauftragte. Petros kehrte zu Paulos zurück und ging anschließend mit dem patriarchalen Schreiben und einem Begleitschreiben des Paulos zu Basileios von Zygos, der ihn zum Priester weihte. Im Rahmen einer Wundergeschichte wird berichtet, daß Paulos zusammen mit Petros zu einer Pilgerfahrt ins Heilige Land aufbrach und auch den Halys erreichte. Jedoch wurde Paulos dann vom Heiligen Geist an der Durchführung seiner Pilgerfahrt gehindert. Statt dessen wurde ihm der Gedanke eingegeben, ein Kloster zu gründen. Paulos und Petros reisten also zurück zum bithynischen Olymp und gründeten dort das Zachariaskloster, dessen erster Abt Paulos wurde. Als Paulos von Mantineion im November/Dezember des Jahres 805/06 erkrankte, setzte er Petros zu seinem Nachfolger und Hegumenos des Zachariasklosters ein. Nachdem Paulos gestorben war (805/06), ließ Petros den Leichnam in der Klosterkirche des Zachariasklosters, die dem Propheten Zacharias geweiht war, feierlich beisetzen

Man sieht, daß es sich im Grunde um eine (fast) vollständige Vita des Paulos von Mantineion, des Lehrers des Petros von Atroa, handelt. Auch wenn die Erzählung in der Vita des Petros von Atroa stets eng mit dem Leben des Petros verknüpft ist, so ließe sich doch die Vita des Paulos aus der des Petros exkorporieren und hätte dann als eigenständiger hagiographischer Text Bestand; sogar die notwendigen Miracula sind in dieser Vita bereits angelegt (capp. 7-11). Das Einzige, was dieser Vita wirklich fehlt, ist ein regelrechtes Proöm. Stattdessen findet sich nur der folgende Einleitungssatz, mit dem der Verfasser - anscheinend beiläufig - die Lebensgeschichte des Paulos eröffnet, nachdem zuvor bereits berichtet wurde, wie Petros dem Paulos begegnet war ${ }^{82}$ : „Aber da wir ja nun des sehr verehrungswürdigen Paulos Erwähnung getan haben, sind wir notwendigerweise gezwungen, auch sein Leben zu berichten und alles im einzelnen aufzuzeigen." Der darauf folgende Satz vermeldet die Herkunft des Paulos und entspricht ganz dem Schema der Eröffnungssätze der Narratio in der Heiligenliteratur ${ }^{83}$ : „Dieser verehrungswürdige Paulos nämlich war aus dem Land der Bukellarier $^{84}, \ldots$... Im Synaxar von Konstantinopel wird Paulos von Mantineion

80 Vgl. PMBZ: 7235 ; C. Ludwig - Th. Pratsch, Tarasios (25. Dezember $784-25$. Februar 806), in Patriarchen $57-108$

81 Vgl. PMBZ: $\# 886$

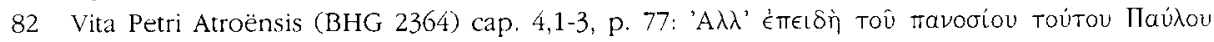

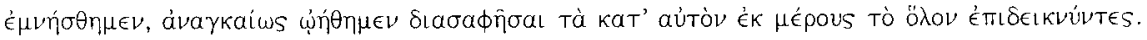

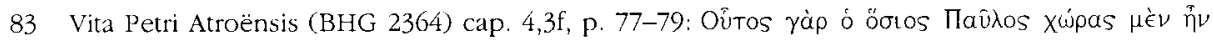

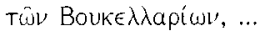

84 Gemeint ist das Thema Bukellarion. 
nicht erwähnt. Wie es scheint, blieb sein Kult also auf das von ihm gegründete Zachariaskloster sowie möglicherweise auf die Mönchskongregation unter Petros von Atroa ${ }^{85}$ beschränkt. Obwohl sie in der Vita des Petros von Atroa (BHG 2364) bereits annähernd vollständig vorlag, wurde seine eigene Vita anscheinend niemals aus der Vita des Petros herausgelöst und bekam so kein hagiographisches Eigenleben.

Im Rahmen der Vita des Theodoros von Edessa (BHG 1744) wird (unter anderem $^{86}$ ) die Lebensgeschichte des Michael Sabbaïtes überliefert ${ }^{87}$ : Er sei aus Edessa zu Theodoros in das Sabaskloster gekommen, auf seine Bitten hin von diesem zum Mönch geschoren worden und habe den Namen Michael erhalten.

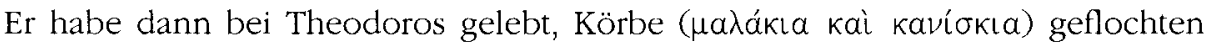
und sie in Jerusalem verkauft. Dort wurde er von einem Diener zu Seìda geführt, der Ehefrau des Kalifen 'Abd al-Malik. Nachdem sie vergeblich versucht hatte, ihn zu verführen, zeigte sie ihn bei ihrem Mann an, woraufhin Michael verhört wurde und mit dem Kalifen über den Glauben diskutierte. Obwohl ihm der Tod angedroht wurde, weigerte er sich, zum Islam überzutreten. Er wurde gefoltert, blieb aber auf wunderbare Weise unversehrt und überlebte auch die Einnahme eines Gifttranks. Schließlich wurde er außerhalb Jerusalems auf dem Hügel des hl. Georg enthauptet. Sein Kopf wurde auf Befehl des Kalifen den Mönchen des Sabasklosters übergeben. Die Geschichte ist zweifellos legendär, obgleich ein Heiliger dieses Namens existiert zu haben scheint ${ }^{88}$. Nach einer singulär nur georgisch überlieferten, aber auf ein arabisches Original zurückgehenden Passio ${ }^{89}$ soll Michael zur Zeit des arabischen Kalifen 'Abd al-Malik' 90 (also zwischen 685 und 705) das Martyrium erlitten haben. Im allgemeinen nimmt man an, daß die Passio in die Vita des Theodoros von Edessa (BHG 1744) übernommen wurde ${ }^{91}$, da sich das Personal der Passio vom Ende des 7. Jh.s, einschließlich des arabischen Kalifen 'Abd al-Malik, unverändert in der Vita

85 Zu dieser Kongregation s. PMBZ: \#6022 (Petros von Atroa).

86 Diese Vita fällt dadurch auf, daß in ihr eine ganze Reihe von Lebensgeschichten anderer (heiliger) Männer berichtet werden. S. dazu noch im folgenden.

87 Vita Theodori Edess. (BHG 1744), cap. XIX-XXXVI, p. 14-31. Vgl. dazu P. Peeters, in: AnBoll 48 (1930) 65f. 77-98; dens., Le tréfonds oriental de l'hagiographie byzantine, Brüssel 1950 (Subs, hag, 26), 185f, 210.

88 Zu Michael Sabbaïtes vgl. PMBZ: \# 5003. Legende ist sicherlich die mißslungene Verführung Michaets durch die Frau des Kalifen, Seida. Die Geschichte ist der alttestamentarischen Verführungsszene zwischen Joseph und der Frau des Potiphar, des Kämmerers und Hauptmanns des Pharao, nachempfunden (Gen 39. 1-20). Dennoch will der russische Pilger Daniel im Jahre 1105/06 die Reliquien des Michael im Sabaskloster in Palästina gesehen haben, vgl. Daniel Igumen, Choždenie (Khitrowo) 34; Itineraria rossica 59

89 Vgl. dazu PMBZ, Prolegomena 211

90 Vgl. PMBZ: $\neq 18$ 
des Theodoros wiederfindet, der erst gegen Ende des 8. Jh.s (etwa zwischen 776 und 793) geboren wurde ${ }^{92}$. Dennoch können wir zumindest festhalten, daß in diesem Falle, dies bestätigt die parallele Überlieferung der Passio, die Lebensgeschichte des Michael Sabbaites innerhalb der Vita des Theodoros von Edessa (BHG 1744) überliefert und bewahrt wurde.

Ein anderer Fall ist die Lebensgeschichte des Theodosios Kionites ${ }^{93}$, die sich nicht en bloc, sondern an verschiedenen Stellen in der Vita des Theodoros von Edessa (BHG 1744) findet ${ }^{94}$. Es handelt sich dabei um eine nicht ganz vollständige Lebensgeschichte des Theodosios. Der Anfang fehlt und die Erzählung beginnt mit der ersten Begegnung zwischen Theodoros von Edessa und dem Kionites, wird aber zusätzlich durch einige Erinnerungen des Theodosios auch auf die Zeit vor der ersten Begegnung der beiden ausgedehnt. Die Lebensgeschichte wird nicht stringent erzählt, sondern ergibt sich aus einer Reihe von Begegnungen und Unterhaltungen - oft in Dialogform und in Form längerer Monologe des Theodosios - an verschiedenen, auch auseinanderliegenden Stellen der Vita des Theodoros von Edessa: Demnach war Theodosios der letzte Stylit in der Region von Edessa. Als Theodoros Bischof von Edessa wurde (vermutlich um 836), war er schon hochbetagt und hatte laut Aussage der Priester von Edessa (p. 53) bereits 95 bzw. nach eigener Aussage (p. 67) 49 Jahre auf seiner Säule verbracht. Als Theodoros ihn besuchte, weissagte Theodosios diesem die Bekehrung des Kalifen Mavias ${ }^{95}$, erzahlte ihm (cap. LVI-LX) die Geschichte des Persers Ader ${ }^{96}$ und gab ihm den Rat, ein Nonnenkloster zu besuchen (cap. LXIII). Ferner berichtete er Theodoros über sein eigenes Leben (cap. LXV-LXVII) und riet ihm zu einer Reise nach Bagdad (cap. LXX). Er selbst habe in seiner Jugend zusammen mit seinem Bruder Ioannes zuerst drei Jahre in einem Kloster verbracht, dann hätten sie auf Anordnung ihres geistlichen Vaters in der Wüste bei Babylon (gemeint ist Bagdad) jeder in einer eigenen Höhle, ca. ein bis zwei

91 Vgl. dazu P. Peeters, in: AnBoll 48 (1930) 65f. 77-98; dens., Le tréfonds oriental de l'hagiographie byzantine, Brüssel 1950 (Subs. hag. 26), 185f. 210.

92 Dieser Umstand spricht zum einen für einen gewissen zeitlichen Abstand zwischen den tatsächlichen Ereignissen und der Abfassung oder Überarbeitung der Vita des Theodoros von Edessa, da man zu diesem Zeitpunkt die chronologischen Widersprüche nicht mehr bemerkte, zum anderen für einen gewissen räumlichen Abstand zwischen dem Abfassungs- oder Überarbeitungsort der Vita und dem Kalifat (Palästina). Dies könnte an eine Abfassung bzw. Überarbeitung der Vita etwa in Konstantinopel denken lassen.

93 Vgl. PMBZ: \# 7877.

94 Vita Theodori Edess. (BHG 1744) cap. LV-LXVIII, p. 52-69; cap. LXX, p. 72f.; cap. LXXIII, p. 79f; cap. CXII, p. 117. Vgl dazu Vasiliev, in: Byz 16 (1942/1943) 181; Delehaye, Saints Stylites CXXIX.

95 Vgl. PMBZ: \# 4875 .

96 Vgl. PMBZ: \# 86. Zu diesem s. noch im folgenden 
Meilen voneinander entfernt, als Einsiedler gelebt. Sie hätten sich von Pflanzen ernährt und sich nur samstags und sonntags getroffen. Eines Tages habe er seinen Bruder ein Stadion oder mehr entfernt in einer Vision gesehen, sei an den

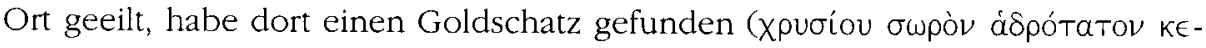

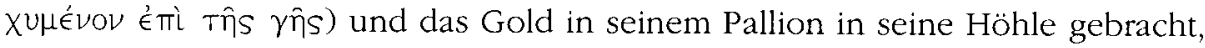
ohne seinem Bruder davon Mitteilung zu machen. Von dem Geld habe er in der Stadt ein ummauertes Grundstück gekauft, dort ein Kloster mit vierzig Mönchen gegründet, einen geeigneten Mann als Abt eingesetzt und bei dem Kloster auch ein Krankenhaus eingerichtet. Das Geld habe er für die Mönche und die Armen verwendet und sei dann zu seinem Bruder zurückgekehrt. Bei seiner Rückkehr in die Wüste habe er seinen Bruder nicht gefunden und am siebten Tag eine Vision gehabt, in der ihm ein Engel befahl, nach Edessa zu gehen und dort auf einer Säule nahe der Kirche des hl. Märtyrers Georgios zu leben und Buße zu tun. Er sei nach vierzig Tagen dorthin gelangt und habe dort 49 Jahre auf der Säule verbracht. Im fünfzigsten Jahr sei ihm am Ostersonntag wieder der Engel erschienen und habe ihm mitgeteilt, daß sein Bruder am Leben sei. Der Engel

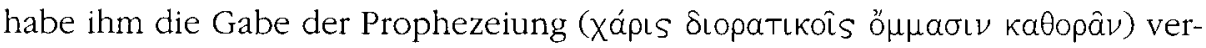
liehen (cap. LXVI). Er schrieb nun einen Brief an seinen Bruder, in dem er die Zukunft voraussagte und den er dem Theodoros auf die Reise nach Bagdad (der Text hat wiederum Babylon) mitgab (cap. LXX). Er wurde von Theodoros nach dessen Rückkehr besucht, erfuhr nach wenigen Tagen vom Tod seines Bruders und starb selbst nach kurzer Krankheit (cap. CXII). Nimmt man die in der Vita des Theodoros von Edessa (BHG 1744) verstreuten Informationen zusammen, ergibt sich also eine relativ umfassende Lebensgeschichte des Theodosios Kionites. Es fehlen allerdings einige wichtige Elemente: Proöm, Herkunft, Elternhaus, Geburt und anderes mehr; Wunder, Visionen und Prophezeiungen sind im Kern bereits angelegt.

Schließlich wird in der Vita des Theodoros von Edessa (BHG 1744) von dem Styliten Theodosios dem heiligen Theodoros die Lebensgeschichte des Ader, der später den Mönchsnamen Athanasios annahm, erzählt97 ${ }^{97}$ Ader lebte in der zweiten Hälfte des 8. Jh.s in Edessa und war von vornehmer Herkunft, vielleicht ein ehemaliger Senator (Synkletikos, seine Frau wird als Synkletike bezeichnet). Er war reich an Geld, Sklaven, Vieh und Dienerschaft. Täglich wurden fünfzig Nomismata für das Essen an seinem Tisch ausgegeben. Gleichzeitig war er mildtätig und liebte die Armen, baute Kirchen, unterstützte die Mönche und andere Bedürftige. Mit seiner Ehefrau hatte er drei Söhne. Eines Tages verkündete er

97 Vita Theodori Edess. (BHG 1744) cap. LVI-LX, p. 56-61. Die Lebensgeschichte des Ader/Athanasios ist folglich innerhalb der Lebensgeschichte des Theodosios Kionites überliefert, die wiederum innerhalb der Vita des Theodoros von Edessa (BHG 1744) überliefert ist! 
dem Theodosios seinen Entschluß, das weltliche Leben zu verlassen. Er ging nach Jerusalem, besuchte dort die heiligen Stätten und trat als Mönch unter dem Namen Athanasios in die Sabaslaura ein. Er erschien kurze Zeit später seiner Frau in einer Traumvision und verkündete ihr, daß er die Kinder zu sich nehmen werde. Auch sie solle sich um ihre Seele kümmern. Er erschien auch dem Theodosios und verkündete ihm, daß die Äbtissin des nahe von dessen Säule befindlichen Klosters in drei Tagen sterben werde. Theodosios solle Aders Frau in das Kloster geben und zu ihrer Nachfolgerin ernennen. Ihr jüngster Sohn werde in die Sabaslaura kommen, Mönch und später Patriarch von Jerusalem werden. Tatsächlich starben wenig später die beiden ältesten Söhne, die Ehefrau wurde Nonne und dann Äbtissin, der jüngste Sohn überlebte eine schwere Erkrankung, wurde Mönch, kam nach dem Tod seines Vaters in die Sabaslaura, wo er bis zu seiner Erhebung zum Patriarchen von Jerusalem in dessen Zelle lebte. Abgesehen von seiner Lebensgeschichte in der Vita des Theodoros von Edessa (BHG 1744) gibt es zu Ader/Athanasios keine weiteren Belege. Ein Kult dieses Sabbaites hat sich anscheinend nicht dauerhaft entwickelt.

In der Vita der Athanasia von Aigina (BHG 180) taucht an einer Stelle, als Athanasia $^{98}$ und andere gleichgesinnte Frauen sich von der Welt zurïickzuziehen wünschen, der Priester Matthias ${ }^{99}$ auf. Dieser ermahnte die frommen Frauen, es mit der Askese nicht zu übertreiben, versprach ihnen aber gleichzeitig, wenn sie seinem Wunsch entsprächen, ihnen einen geeigneten Ort für ihr frommes Leben zu zeigen. Matthias führte die Frauen an einen Ort, an dem sich eine Kirche des Protomärtyrers Stephanos befand. An dieser Stelle schweift der Verfasser etwas ab von der Darstellung des Lebens der heiligen Athanasia und widmet sich recht eingehend der Darstellung des Lebens des Matthias ${ }^{100}$ : „Der selige Matthias nun brachte mit Billigung des örtlichen Bischofs die Frauen dort unter und ließ ihnen jedwede Fürsorge angedeihen. Auch er selbst pflegte größte Askese und Enthaltsamkeit und wachte viele Nächte. Die ganze Nacht lang sagte er dann den Psalter auf und betete ohne Unterlaß. Er schlief nicht ausgestreckt, sondern erfülte im Sitzen die Notwendigkeit des Schlafes. So groß war seine Zerknirschung beim Gesang der Psalmen und bei der Darbringung des göttlichen und unblutigen Opfers, daß die, die ihn sahen, großen Nutzen daraus zogen. Er begnügte sich mit nur einem Gewand, das innen von härener Rauhheit war und ihm beim Tragen heftig das Fleisch geißelte. Er hatte eine besondere Vorliebe für Ioannes, den Vertrauten des Herrn. Wenn dessen heiliges Gedenken herankam, wollte er die unblutige Liturgie feiern und wurde davon

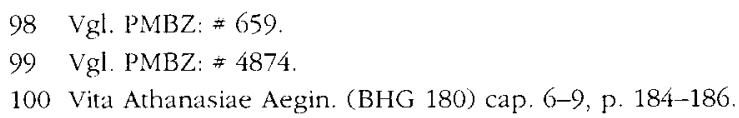


ganz erfüllt und über alle Maßen zerknirscht. Und er sagte zu einem von denen, die bei ihm waren: 'Gibt es einen Menschen, der am heutigen Tage würdig genug wäre, den heiligen Apostel Ioannes, in Ephesos angekommen, zu sehen?' Und da er dies sagte, flossen Ströme von Tränen aus seinen Augen, und Seufzer entrangen sich seinem Herzen. Es geschah nun eine Sache, die seiner Liebe zu dem Jünger des Herrn würdig war: Vom Beginn der göttlichen Liturgie an bis zu ihrer heiligen Vollendung sah er den Apostel am heiligen Altar selbst stehen. Nicht nur er sah ihn, sondern auch zwei weitere, die mit ihm zusammen das unblutige Opfer feierten. Bis zum dritten Tag war er nun so von Zerknirschung ergriffen, daß er keine menschliche Nahrung zu sich nehmen konnte. Zu diesem seligen Matthias kam nun ein Mann, der am ganzen Körper gelähmt war. Dieses

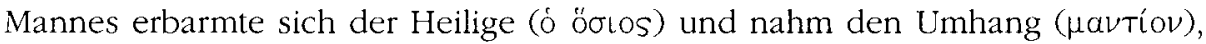
den er umgelegt hatte, ab und legte ihn dem Mann um die Schultern. Nachdem dies geschehen war, gaben die Glieder des Körpers des Mannes ein lautes, kreischendes Geräusch von sich, und sogleich wurde er gesund. Einem anderen Mann, dessen Antlitz durch das Wirken des Teufels entstellt war, schenkte Matthias die Heilung durch das Siegel (sc. das Kreuzeszeichen) seiner würdigen Hand. Doch auch einer greisen Frau, die von einem unreinen Geist ergriffen war und zu dem seligen Matthias kam, schenkte Gott in wenigen Tagen durch seine unaufhörlichen Gebete die Gesundheit. Und eine andere Frau, die das Gewand einer Nonne trug und von einem unreinen Geist heimgesucht wurde, nahm er in das Kloster auf. Als nun der Heilige (ó örıs) plötzlich hereinkam und sah, wie diese ganz allein in der Kirche war und litt, erbarmte er sich ihrer, erhob die Hände zum Himmel, betete in ausreichendem Maße und machte über ihr dreimal das Siegel des Kreuzes. Als dies geschehen war, flüchtete jener elende Dämon, die Nonne aber blieb von nun an gesund. Wir haben dies aufgezählt, um die Höhe des Lebenswandels des Mannes zu zeigen und die ihm von Gott gegebene Gnade der Zeichen (sc. die Wundertätigkeit) allen offenbar zu machen. Aber wehe, ich weiß nicht, wie ich es sagen soll. Diesen so heiligen (ä $\gamma(0 \nu)$ und Gott geweihten Mann ereilte, als er ein Schiff bestieg und in die kaiserliche Großstadt segelte, eines jener Urteile, deren Sinn allein Gott kennt: Zusammen mit seinen Reisegefährten ertrank er in den Wogen des Meeres. Daher wurden wir seines heiligen (áyíov) Körpers nicht teilhaftig und haben nicht jenen heiligen und seligen Körper im Sarg, der uns so viele Wohltaten erwies. Allen nämlich schenkte er, als er noch im Fleische wandelte, in reichem Maße die Wirksamkeit der Heilungen. In noch größerem Maße gewährte er sie, nachdem er heimgegangen war, denen, die zu ihm kamen, so als ob sie seinen Leichnam berühren würden." Wir haben hier also eine Lebensbeschreibung des Matthias vor uns. Dieser fehlen im Vergleich zu einer vollständigen Heiligenvita zwar noch eine Reihe von Elementen, aber sie hat bereits Wunder vorzuweisen. Man 
kann also festhalten, daß der Keim einer Vita des Matthias im Rahmen der Vita der Athanasia angelegt ist. Dies zeigt wohl, daß der Kult der Athanasia zum Zeitpunkt der Abfassung ihrer Vita bereits größer war als der Kult des Matthias, den es aber anscheinend, vermutlich auch in der genannten Protomartys-StephanosKirche in Timia auf Ägina, ebenfalls gegeben hatte. Die Lebensbeschreibung des Matthias erklärt gleichzeitig auch die nicht alltägliche und vermutlich Fragen provozierende Verehrung eines Kenotaphs (des Matthias) in jener Kirche, in der auch die heilige Athanasia beigesetzt war und verehrt wurde. Es läßt sich nicht mit Sicherheit sagen, ob die Vita des Matthias jemals aus der Vita der Athanasia extrapoliert und anschließend weiter elaboriert wurde. Eine eigene Vita des Matthias ist jedenfalls nach heutigem Kenntnisstand nicht erhalten, er wird aber auch, ebenfalls im Rahmen einer Kurzvita der Athanasia von Ägina, in einer Hs. des Synaxars von Konstantinopel genannt ${ }^{101}$.

Ferner sei hier noch kurz auf das Beispiel der Lebensbeschreibung des ehemaligen Räubers und späteren Mönchs Ioannes ${ }^{102}$ hingewiesen, die innerhalb der Vita des Antonios des Jüngeren (BHG 142) überliefert wird ${ }^{103}$ : Ioannes lebte gegen Ende des 8 . Jahrhunderts und war zunächst Anführer einer Räuberbande

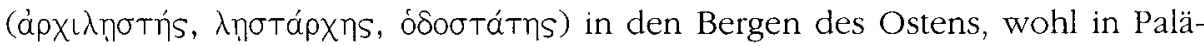
stina. Auch wenn er sich nicht immer christlich benahm, so war er doch Christ. Das Weihnachtsfest verbrachte er regelmäßig in Jerusalem. Eines Tages hörte er,

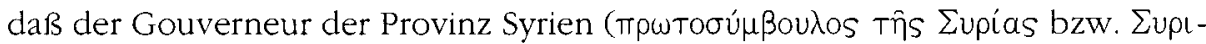
(apxos) einen Äthiopier besaß, der stärker als alle anderen war, und einen Preis für denjenigen ausgesetzt hatte, der den Äthiopier besiegen würde. Ioannes forderte den Äthiopier zum Kampf, besiegte und tötete ihn und wurde reich beschenkt. Später wurde er Mönch im Sabaskloster bei Jerusalem, wo er zehn Jahre lebte, um sich dann als Eremit in den Bergen bei Phossaton niederzulassen. Er bekehrte dort einen Juden zum Christentum und ließ ihn taufen. Der heilige Antonios der Jüngere wurde in kindlichem Alter zu ihm geschickt, und Ioannes sagte ihm die Zukunft voraus. Später verfolgte Ioannes aus der Ferne das Wirken des Antonios. Im Jahre 825 schickte er ihm einen Brief und ermahnte ihn, nicht, wie beabsichtigt, zu heiraten, sondern Mönch zu werden, was Antonios auch befolgte. Es handelt sich hier um eine vergleichweise rudimentär entwickelte "Lehrervita" in der Vita des Schülers ${ }^{104}$. Andere Beispiele für dieses Schema ("Vita patris in vita filii“) sind uns oben bereits begegnet ${ }^{105}$, ebenso wie der umgekehrte Fall (,vita filii in vita patris") ${ }^{106}$.

101 Vgl. Synax. Cpl. 613/614,35-39.

102 Vgl. PMBZ: \# 3140.

103 Vita Antonii iun. (BHG 142) cap. 3-9, p. 188,3-192,30; cap. 19, p. 200,15f.; cap. 20, p. 201,322. 
Man kann auf der Grundlage der genannten Beispiele also feststellen, daß in etlichen Fällen in den größeren, elaborierten Heiligenviten auch Lebensgeschichten oder Viten in nuce anderer (potentieller) Heiliger angelegt waren. Häufig handelte es sich bei den Protagonisten dieser Lebensgeschichten um Lehrer oder Schüler des Protagonisten der Rahmenvita, bisweilen bleibt die Beziehung des Protagonisten der Vita in nuce zum Protagonisten der Rahmenvita aber auch unklar oder läßt sich gar als konstruiert bzw. fiktiv erweisen. Eine solche Vita in nuce konnte später aus dem Kontext der Rahmenvita herausgelöst, weiter elaboriert und schließlich zu einer vollständigen Heiligenvita ausgearbeitet werden. Dies geschah jedoch nur in Abhängigkeit von der Entstehung eines Kultes ${ }^{107}$ des Protagonisten. Die hier behandelten Lebensbeschreibungen sind nur innerhalb der Rahmenvita erhalten. Entweder kam es in diesen Fällen nicht zur Entwicklung eines eigenständigen Kultes oder dieser blieb regional begrenzt und war nur von kurzer Dauer.

104 Rydén, New Forms 543, vermutete, daß es sich ursprünglich um eine eigenständige Vita gehandelt haben könnte, die vom Verfasser der Antoniosvita teilweise übernommen worden sei. Auf diese Idee kann man kommen, wenn man die Antoniosvita isoliert betrachtet, sie verliert aber an Überzeugungskraft, wenn man die doch beachtliche Zahl von Beispielen für "vita patris in vita filii" in den Blick nimmt.

105 Nämlich die Vita des Paulos von Mantineion in der Vita des Petros von Atroa (BHG 2364-2365) und die Vita des Matthias in der Vita der Athanasia von Ägina (BHG 180); weitere Beispiele: Vita Stephani iun. (BHG 1666) cap. 11-17, p. 102-107 (Vita des Ioannes in der Vita des Stephanos); Vita Lazari Galesiotae (BHG 979) cap. 37-40, p. 520-522 (Vita des Paphnutios). Vgl. Delehaye, Méthode 33-37.

106 Nämlich die Vita des Michael Sabbaïtes in der Vita des Theodoros von Edessa (BHG 1744), auch wenn hier das Lehrer-Schüler-Verhältnis fiktiv zu sein scheint, ferner die Vita des Ader in der Vita des Theodosios Kionites in der Vita des Theodoros von Edessa (BHG 1744). Ein weiteres Beispiel dafür sind die Lebensgeschichten der Theodoros und Theophanes Graptos in der Vita des Michael Synkellos (BHG 1296) cap. 5, p. 52,15 - 54,22; cap. 8-14, p. 60,1 - 72,6; cap. 17-24, p. 74,22 - 98,24; cap. 30-31, p. 110,23 - 114,21; vgl. dazu Sode, Viten bes. 147. 158-161. 207-220. 225-236. 247-250; weitere Beispiele: Vita Theod. Cyth. (BHG 2430) p. $287,180-288,229$ (Vita des Antonios in der Vita des Theodoros); Vita Mariae iun. (BHG 1164) cap. 24, p. 701C; cap. 26-27, p. 702C-703A; cap. 30-31, p. 703F-704B (Vita der Söhne Baanes/Marinos und Stephanos/Symeon: vita filiorum in vita matris, in diesem Falle handelt es sich auch um die leibliche Mutter); Vita Euthymi patr. (BHG 651) cap. 16, p. 105-109 (Vita des Niketas David Paphlagon in Vita des Euthymios. Vgl. Delehaye, Méthode 33-37. - Beide Formen (Lehrervita und Schülervita) dienen natürlich auch dem erzählerischen Zweck, den Hl. fest im Chor der Heiligen zu verankern, indem seine Lehrer und/oder Schüler ausführlicher gewürdigt werden. S. dazu auch bereits oben Kap. $5:$; $\$ 4$. Unterordnung: B. Dienst bei einem Lehrer", und Kap. 10: "§ 1. Jünger und Schüler".

107 Zur Kultentwicklung vgl. Calendine, Theosis 88-139; zur Rolle von Wundern 119-121, auch 151ff. Vgl. auch Aigrain, Hagiographie 82f. 


\section{Entstehung aus anderen literarischen Formen}

Aber auch andere, kleinere und bisweilen nicht exakt zu bestimmende literarische Formen konnten anscheinend den Kern einer späteren schrittweisen Elaboration einer Heiligenvita bilden. Dafür finden sich zumindest einige Hinweise:

Im Proöm der Vita des Theodoros Studites (BHG 1754) berichtet der Verfasser, der Mönch Michael, daß bereits vor ihm einige literarische Werke geschaffen worden seien, die in verschiedener Form das Andenken des großen Mönchsvaters geehrt hätten ${ }^{108}$ : „Doch auf welche Weise jener berühmte Lehrer und Vater sein Leben bei uns führte, haben einige seiner Schüler in Form von schönen Gesängen gleich nach seinem Ableben angedeutet, indem sie die vielfältigen guten Taten seines ausgedehnten und allerhöchsten Lebenswandels in der knappen Sprache von Versen zusammenfaßten. Nach diesen haben auch andere der Priester der Kirche in der Form eines Geschichtswerks und in der Gestalt von Lobreden in sehr schöner und ausführlicher Weise sein Andenken zusammengestellt und bis ins höchste Alter als ein Mittel gegen das Vergessen wie einen Schatz gehütet." Michael gibt also an, was ihm bereits vorlag, als er von den Vätern des Studiosklosters beauftragt wurde, eine vollgültige Vita des Theodoros in einfacher und verständlicher Sprache abzufassen ${ }^{109}$. Wir dürfen davon ausgehen, daß er diese Vorlagen zum einen als Quellen benutzte, sie zum anderen aber auch zumindest teilweise elaborierte und in seine Vita integrierte. Michael unterscheidet dabei zwei bis drei verschiedene literarische Formen, die ihm vorlagen:

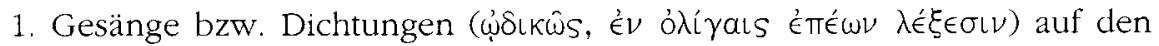

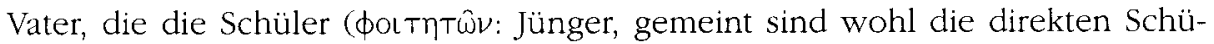
ler) des Theodoros abgefaßt hätten. Es liegt mehr als nahe, daß es sich dabei um hymnographische Werke handelte ${ }^{110}$. Michael selbst gibt die Nachteile dieser Literatur an: Die Gesänge bzw. Dichtungen hätten die großen Werke des Theodo-

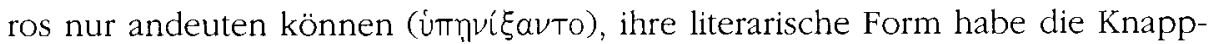

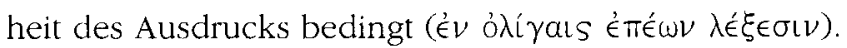

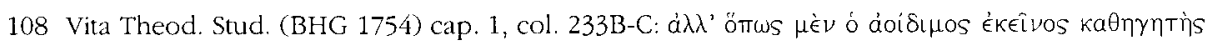

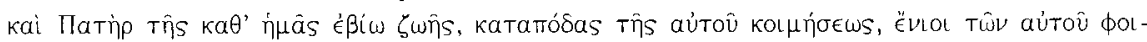

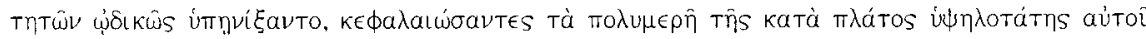

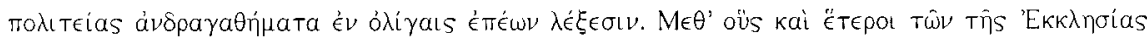

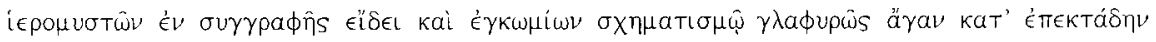

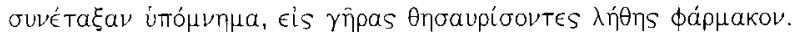

109 Vgl. Vita Theod. Stud. (BHG 1754) cap. 1, col. 233C-236B.

110 Gerade im 9. Jh. blühte im Studioskloster in Konstantinopel eine regelrechte Schule der Hymnographie und sind eine ganze Reihe von Hymnographen des Studiosklosters in den Quellen greifbar, vgl. dazu Pratsch, Theodoros 306 mit Anm. 12 (dort weitere Literatur). 
2. Prosaschriften bzw. Geschichtswerke ( $\left.\epsilon \nu \sigma u \gamma \gamma \rho a \phi \eta \hat{s} \epsilon^{\prime \prime} \delta \epsilon L\right)$, die von einigen "der Priester der Kirche" ( seien. Gemeint ist damit wohl, daß hier der Rahmen des Studiosklosters überschritten wurde, und daß einschlägige geistliche Literaten sich des Themas der guten Taten des Theodoros angenommen hatten. Was die Werke selbst betrifft, so bleibt im unklaren, worum es sich im einzelnen handelte. Abhandlungen zu bestimmten Lebensabschnitten des Theodoros, etwa sein Translationsbericht ${ }^{111}$ oder ähnliches, scheinen hier am ehesten in Frage zu kommen.

3. Lobreden ( $(\dot{\gamma} \gamma \kappa \omega \mu \hat{i} \omega \nu \sigma \times \eta \mu \alpha \tau \iota \sigma \mu \omega)$ ), die ebenfalls von den „Priestern der Kirche" verfaßt worden waren. Der Text ist an dieser Stelle nicht eindeutig in der Frage, ob die Enkomia nur eine nähere Beschreibung der Prosaschriften bzw. Geschichtswerke sind oder eine eigene literarische Gattung darstellen. Wenn sie als eigene literarische Gattung zu betrachten sind, dann dürfte es sich am ehesten um kleinere hagiographische Formen, also etwa Mnemai bzw. Kurzviten, gehandelt haben.

Es dürfte zumindest deutlich geworden sein, daß, abgesehen von den bereits zuvor genannten, auch andere, kleinere literarische Formen die Grundlage einer weiteren Elaboration und somit zur Entstehung einer einzelnen Heiligenvita geboten haben könnten.

\section{Auftragsarbeit}

Die zahlreichen Anhaltspunkte dafür, daß auf der einen Seite eine beträchtliche Zahl von Heiligenviten gerade nicht en bloc niedergeschrieben, sondern schrittweise, über verschiedene Bearbeitungsstufen und teilweise aus anderen literarischen Formen entwickelt wurden, dürfen natürlich keineswegs den Blick dafür verstellen, daß auf der anderen Seite eine große Zahl von Heiligenviten tatsächlich auf die eingangs beschriebene idealtypische und konventionelle Weise entstanden. Das heißt, sie wurden nicht lange nach dem Tod des Heiligen - der zeitliche Abstand dürfte in der Tat unterschiedlich gewesen sein und zwischen wenigen Tagen und einigen Jahren gelegen haben - auf Veranlassung des Abts oder eines anderen Auftraggebers durch einen spezialisierten Hagiographen in einem Stück niedergeschrieben.

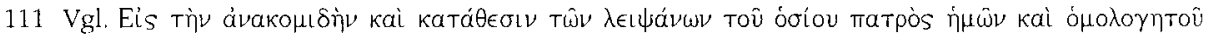

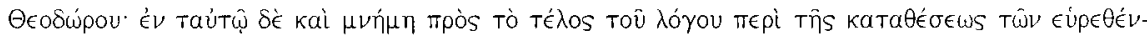

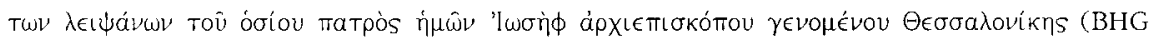
1756t), ed. Ch. van de Vorst, La Translation de S. Théodore Studite et de S. Joseph de Thessalonique, in: AnBoll 32 (1913) 50-61 (Text). 
In den Viten, bei denen dies der Fall ist, findet sich häufig ein Hinweis auf den Auftraggeber ${ }^{112}$. Ferner sind die Texte inhaltlich-stilistisch kohärent und weisen keine auffälligen Brüche und Zäsuren auf. Wunder sind in die Erzählung an verschiedenen Stellen eingewoben und nicht als kleine Sammlungen an einer Stelle der Vita, den Fortgang der Narratio unterbrechend, inseriert. Die Tatsache der Entstehung einer Vita als Auftragsarbeit nicht lange nach dem Tod des Heiligen ist im Grunde unstrittig ${ }^{113}$. Sie kann deshalb hier mit einigen wenigen Belegen auskommen, die wiederum jeweils ihre Besonderheiten aufweisen:

1. die Vita des Stephanos des Jüngeren (BHG 1666): Die Vita darf als eine typische Auftragsarbeit gelten, auch wenn unlängst in der Forschung diskutiert wurde, ob es nach 843 eine spätere Überarbeitung der ursprünglich wohl im Jahre 809 entstandenen Fassung gegeben hat oder nicht ${ }^{114}$. Die Herausgeberin, Marie-France Auzépy, spricht sich gegen eine spätere Überarbeitung aus. Sie hat die Kohärenz des Textes genau untersucht und kam zu dem Ergebnis, daß es sich um das Werk nur eines Verfassers handelt. Demnach ist die Vita 42 Jahre nach dem Tod des Heiligen, wohl im Jahre 809, im Auftrag des Hegumenos Epiphanios $^{115}$ von dem Diakonos Stephanos vermutlich in Konstantinopel unter Benutzung zahlreicher Vorlagen ${ }^{116}$ niedergeschrieben worden ${ }^{117}$. Der Anlaß der Abfassung dürfte in dem Versuch zu sehen sein, zu diesem Zeitpunkt einen Stephanoskult in einem der Klöster am Auxentiosberg zu begründen oder zu beleben $^{118}$.

2. die Vita des Patriarchen Tarasios (BHG 1698): Auch bei dieser Vita handelt es sich um eine Auftragsarbeit ${ }^{119}$. Sie wurde von Ignatios Diakonos ${ }^{120}$ nach der Wiedereinführung der Ikonenverehrung im Jahre 843, recht wahrscheinlich $843 / 44^{121}$, möglicherweise im Pikridionkloster bei Konstantinopel ${ }^{122}$ abgefaßt. Es ist gut möglich, daß der damals amtierende Patriarch Methodios (843-847) den Auftrag zur Abfassung der Vita des zwischen 815 und 843 nicht kommemorierten verdienstvollen Patriarchen Tarasios ${ }^{123}$ an Ignatios Diakonos vergeben

112 Vgl. aber oben Erster Teil, Kap. 1: „Prooimia“, $\$ 2$ "Bescheidenheitstopos", B. „Auftragstopos", S. $26-28$

113 Sie wird allerdings zu sehr verallgemeinert und auch bei Viten vorausgesetzt, die eben gerade nicht auf diese Weise entstanden.

114 Vgl. Auzépy, Étienne $5 f$.

115 S. dazu Auzépy, Étienne 18.

116 Vgl, Auzépy, Hagiographie 95-120.

117 Vgl. Auzépy, Étienne 5-19; PMBZ: \# 7055 (Stephanos Diakonos).

$118 \mathrm{Vgl}$. Auzépy, Étienne 13-19; zu den Klöstern am Auxentiosberg vgl. Janin, Centres 43-50.

119 Vgl. Efthymiadis, Hagiographical Work 82f.; dens, in: Vita Tarasii (BHG 1698) 48-50.

120 Vgl. Pratsch, Ignatios 82-101; PMBZ: \#2665 (Ignatios Diakonos).

121 Also wenigstens 37 Jahre nach dem Tod des Patriarchen im Jahre 806.

122 Vgl. Pratsch, Ignatios 97 mit Anm. 77. 
hatte. Die beiden kannten einander persönlich ${ }^{124}$, Ignatios Diakonos stand noch immer in einem guten Ruf als Literat, auch als Hagiograph ${ }^{125}$. Die von Ernst von Dobschütz vermutete Identität des im Epilog der Tarasiosvita erwähnten Auftraggebers, des „Dieners Gottes“ ( $\theta \in \mathrm{O} u \hat{~} \theta \in \rho a ́ \pi \omega \nu)$, mit dem Patriarchen Metho$\operatorname{dios}^{126}$ ist jedoch zurückzuweisen. Der Kontext der Erwähnung des $\theta \in \mathrm{ov}$ $\theta \epsilon \rho a ́-$ $\pi \omega \nu$ im Epilog der Vita lautet folgendermaßen ${ }^{127}$ : „Es ist gerecht, daß wir nun im übrigen das Wort an dich richten, Diener Gottes, wer auch immer du bist, der du uns zu dieser Aufgabe gegen unseren Willen angetrieben hast und uns gezwungen hast zu unternehmen, was über unsere Kräfte geht. Nimm unseren Gehorsam entgegen und, wenn du auf die Ärmlichkeit der Rede und die mangelnde Schönheit des Wortes blickst, mögest du nicht die Schrift wegen ihrer Unzulänglichkeit verwerfen." Dabei handelt es sich, im Rahmen der Topik des Epilogs ${ }^{128}$, um die Anrufung des zukünftigen, anonymen Lesers bzw. Hörers, die dann zum Bescheidenheitstopos des unfähigen Autors hinüberleitet. Der "Diener Gottes" 129 ist also jener anonyme, zukünftige Leser, dem vom Verfasser unterstellt wird, er habe - durch seinen aus Frömmigkeit herrührenden Wissensdurst - den Verfasser zur Übernahme dieser Aufgabe angespornt, ja sogar gegen seinen Willen gezwungen. Dies alles ist Auftragstopos! Der "Diener Gottes" kann daher nicht mit einer konkreten Person der Zeitgeschichte identifiziert werden ${ }^{130}$. Ungeachtet dessen könnte Patriarch Methodios aber tatsächlich der Auftraggeber zur Abfassung der Tarasiosvita gewesen sein, jedoch lassen sich dafür keinerlei Beweise erbringen. Der wirkliche Auftraggeber muß somit im dunkeln bleiben. Es könnte sich dabei ebenso um einen anderen Kleriker des Patriarchats von Konstantinopel gehandelt haben, und auch die Möglichkeit,

123 Vgl. Pratsch, Fact and Fiction 67.

$124 \mathrm{Vgl}$. Pratsch, Ignatios 99.

$125 \mathrm{Vgl}$. Pratsch, Ignatios 96-99.

126 Vgl. Dobschütz, Methodios 59: „..., das war das Programm des Patriarchen Methodios. Es scheint mir fast sicher, daß dieser der ungenannte Auftraggeber ist, an den sich Ignatios am Schlußs wendet"; diese Vermutung von von Dobschütz scheint von Efthymiadis, Hagiographical Work 83 und in: Vita Tarasii (BHG 1698) 49, als Tatsachenbehauptung fehlinterpretiert worden zu sein.

127 Vgl. auch die engl. Übers. von S. Efthymiadis, in: Vita Tarasii (BHG 1698) 206; Vita Tarasii

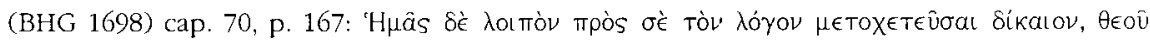

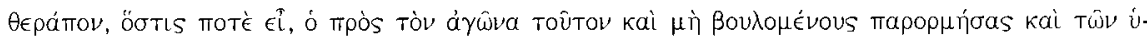

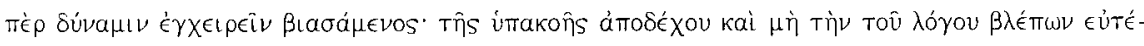

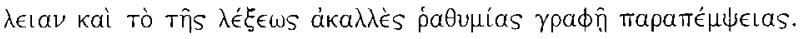

128 S. dazu oben Erster Teil, Kap. 16: „Epilogoi“, S. 340-353.

129 Antizipiert wird hier scheinbar ein Mönch oder Kleriker, doch trifft die Bezeichnung „Diener Gottes" auf jeden Christen zu.

130 Es ist undenkbar, daß Ignatios mit dem Ausdruck "wer auch immer du bist" den Patriarchen von Konstantinopel Methodios meinte, den er persönlich kannte. 
daß Ignatios Diakonos sich selbst diesen Auftrag erteilt hat, um damit seine Karriere als ikonoklastischer Kleriker zu sühnen, ist nicht völlig auszuschließen ${ }^{131}$.

3. die Vita des Platon (BHG 1553): Auch die Vita des Platon von Sakkudion ${ }^{132}$ erfüllt die Kriterien einer Auftragsvita, die „nicht lange nach dem Tod des Heiligen von einem seiner Vertrauten in einem Stück niedergeschrieben wurde". Es wurde oben schon festgestellt, daß diese Vita einen Zwischenschritt zwischen einem Epitaphios Logos und einer Heiligenvita darstellt ${ }^{133}$. Die Annahme liegt sehr nahe, daß der Verfasser der Vita und Neffe Platons, der Abt des Studiosklosters Theodoros, zur ersten Wiederkehr des Todestages Platons $(\uparrow 4$. April 814) einen Platonkult im Studioskloster in Konstantinopel zu begründen trachtete. Theodoros schrieb daher irgendwann zwischen dem 4. April 814 und 815 die Vita des Platon. Die Vita enthält keine postumen Wunder, die sich etwa am Grab Platons (er war im Narthex der Ioannes-Prodromos-Kirche des Studiosklosters in Konstantinopel beigesetzt) ereignet hätten, wahrscheinlich weil sich solche noch nicht zugetragen hatten. Ob die Gedächtnisfeier am ersten Todestag des Platon stattfinden konnte und die Vita in diesem Rahmen zur Verlesung kam, bleibt deshalb fraglich, weil dieses Datum (4. April 815) bereits mit den Unruhen um das erneute Verbot der Ikonenverehrung zeitlich zusammenfiel ${ }^{134}$. Dies und die Tatsache, daß der Kult des Platon nach dem Tode des Theodoros ( $f$ 11. November 826; Translation seines Leichnams in das Studioskloster 26. Januar 844) sicherlich im Schatten des Kultes des Theodoros stand, könnte eine Erklärung dafür darstellen, daß die Vita des Platon später nicht weiter entwickelt und etwa um die notwendigen Wunder erweitert wurde.

\section{\2. Die literarischen Vorbilder}

Im allgemeinen sind die literarischen Vorbilder der byzantinischen Heiligenviten vielgestaltig, da sich die christliche hagiographische Literatur auf der Grundlage der vielfältigen antiken literarischen Tradition entwickelte. Im besonderen lassen sich für einzelne Elemente der hagiographischen Literatur die literarischen Vorläufer genauer bestimmen. Die im Detail häufig recht komplizierte Problematik kann hier jedoch nur exemplarisch und grob umrissen werden ${ }^{135}$ :

131 Vgl. Pratsch, Ignatios $97 f$.

$132 \mathrm{Vgl}$. zu ihm PMBZ: \#6285.

133 S. oben S. 379f,

134 Vgl. dazu Pratsch, Theodoros 231-234 und 247 


\section{Vorchristliche und neutestamentliche Vitenliteratur}

Das literarische Genus der Vita, also die Form der Lebensbeschreibung einer in irgendeiner Weise herausragenden (heiligen) Persönlichkeit von deren Geburt bis zu deren irdischen Tod und möglicherweise Vergöttlichung, hatte um die Zeitenwende bereits eine beachtliche, längere Tradition. In der griechischen Literatur läßt sich diese Tradition zumindest bis zu den antiken Heroen- und Philosophenviten zurückverfolgen, in der hebräisch-jüdischen Literatur bis zu den Lebensbeschreibungen der Könige und Propheten im AT ${ }^{136}$. Rein formal gehören auch die vier Lebensbeschreibungen des Jesus Christus von Nazareth, die kanonischen Evangelien des NT, zum literarischen Genus der Vita, auch wenn sie nicht alle eine vollständige Lebensbeschreibung bieten ${ }^{137}$. Ferner sind auch die Apostelgeschichte sowie einige der apokryphen Evangelien und Apostelgeschichten ${ }^{138}$ zumindest partiell diesem Genus zuzurechnen.

\section{Märtyrerliteratur}

In der Zeit der Verfolgung des frühen Christentums entstand in ursprünglich vielfältigen Formen - Briefe, Passiones, erzählerische Darstellungen und Ak$\operatorname{ten}^{139}$ - eine Literatur, die sich der Beschreibung und literarischen Verbreitung

135 Dabei ist für den hier behandelten Zeitraum nicht notwendigerweise eine große Diskrepanz zwischen lateinischer und griechischer hagiographischer Literatur anzunehmen. Die Entwicklung verlief zunächst noch, wenn auch in verschiedenen Sprachen, in einer organischen Verbindung: Es gab nur eine katholische und orthodoxe (also: allumfassende und rechtgläubige) Christenheit mit, von regionalen Differenzierungen einmal abgesehen, übereinstimmender oder zumindest recht ähnlicher religiöser Praxis; folglich gab es auch nur eine hagiographische Literatur, wenngleich diese in verschiedenen Sprachen abgefaßt werden konnte. Neben Griechisch und Latein kommen hier auch Syrisch, Armenisch, Georgisch, Koptisch, Äthiopisch, Altkirchenslavisch und andere Sprachen in Frage. Aus diesem Grunde können etwa die Ergebnisse der Untersuchungen von René Aigrain, Dieter von der Nahmer, Otmar Kampert und anderen Forschern vornehmlich zur lateinischen hagiographischen Literatur ohne größere Modifizierungen auch für die byzantinische hagiographische Literatur übernommen werden. Vgl. im allgemeinen F. Leo, Die griechisch-römische Biographie, Leipzig 1901; vgl. jetzt auch Krueger, Wri ting $15-62$

136 Vgl. Bieler, Theios aner II, 3-39: "Jüdisch-Christliches".

137 Ihr primäres Ziel ist nicht die Wiedergabe einer vollständigen Lebensbeschreibung, sondern die Vermittlung des Glaubens, vgl, Joh 20. 31, dennoch benutzte vor allem Lukas gerade die literarische Form der griechischen Vita, um dieses Ziel zu erreichen (Matthäus und Markus stammen aus dem aramäischen Raum).

138 Vgl. TRE 3 (1993) 316-362.

139 Vgl. LThK 6 (1997) 1437-1439, s. v. „Martyrer, Martyrium. II. Literarisch“; vor allem Delehaye, Passions passim. 
und Verewigung des Martyriums einzelner Personen oder Gruppen von Personen gewidmet hatte ${ }^{140}$. Der aufkommende Brauch der Märtyrerverehrung und des jährlichen Märtyrergedenkens an deren Todestag einschließlich der öffentlichen Verlesung ihres Martyriumsberichts im Gottesdienst führte im Laufe der Zeit zu einer zweckbedingten Normierung dieser Texte. Es entstanden wiederholbare - die Briefform schied damit aus - Martyriumsberichte und Märtyrerakten, die immer mehr Elemente eines Lebensberichts des Märtyrers aufnahmen und ihre Protagonisten zu siegreichen Heroen überhöhten.

\section{Antike Rhetorik}

Das frühe Christentum der ersten nachchristlichen Jahrhunderte, etwa bis zum 4. Jahrhundert, adaptierte die heidnisch-antiken Sitten und Gebräuche ebenso wie die heidnisch-antiken literarischen Formen, besser gesagt, füllte es die heidnisch-antiken Sitten und Gebräuche und literarischen Formen erfolgreich mit christlichen Inhalten. In diesem Zusammenhang wurden auch bestimmte Elemente und Formen der antiken Rhetorik maßgeblich für die sich entwickelnde christliche Heiligenliteratur. Dies betrifft die Elemente des Enkomions, vor allem des Basilikos Logos, der Lobrede auf einen Herrscher ${ }^{141}$, sowie einige, aber nicht sämtliche Elemente des antiken Epitaphios Logos ${ }^{142}$.

\section{Christliche Vitenliteratur}

Auf dem Fundament der heidnisch-antiken Literatur, vor der literarischen Schablone vor allem der vorchristlichen Vitenliteratur - der paganen griechischen Heroen- und Philosophenviten auf der einen und der hebräischen Vitenliteratur des AT auf der anderen Seite - und anderer vorchristlicher literarischer Muster des Enkomions, insbesondere des Basilikos Logos, und des Epitaphios Logos -, stark beeinflußt durch die Vitenliteratur des NT und die Märtyrerliteratur, formte und entwickelte sich bis etwa zum 4. nachchristlichen Jahrhundert eine eigene, christliche Vitenliteratur: die Hagiographie ${ }^{143}$.

140 Vgl. auch Aigrain, Hagiographie, première partie - les sources de l'hagiographie, 11-192, der bes. 107-131 noch weitere literarische Einflüsse auf die in Entstehung begriffene Hagiographie benennt.

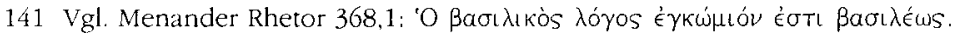

142 Vgl. Menander Rhetor 368,1 - 377,30: Enkomion: Basilikos Logos; 418,5 - 422,4: Epitaphios Logos.

143 Vgl. dazu auch M. van Uytfange, L'hagiographie: une ,genre" chrétien ou antique tardif?, in: AnBoll 111 (1993) 135-188. 
Als Abschluß und vorläufiger Höhepunkt der literarischen Herausformung und Entwicklung der Hagiographie wird in der Forschung allgemein die Vita des Antonios (BHG 140) des Athanasios von Alexandreia angesehen, die in den Jahren 356-373 nach Christus geschrieben wurde. Diese Vita sollte zum Maßstab und literarischen Vorbild für zahlreiche spätere hagiographische Schöpfungen werden. In den darauffolgenden Jahrhunderten und mit dem ständigen Anwachsen des hagiographischen Bestandes sollten dann generell immer wieder ältere Viten das literarische Vorbild für jüngere Viten darstellen.

\section{$\$ 3$. Der rhetorische Aufbau}

Der rhetorische Aufbau einer Heiligenvita entspricht den rhetorischen Normen für die Komposition eines Enkomions ${ }^{144}$. Eine Erläuterung dazu findet sich etwa bei Menander Rhetor, der im Rahmen seiner zwei Abhandlungen zur epideiktischen Rede unter der Überschrift „Über die Grabrede“ (П૯рi émitaфíou) folgendes feststellt ${ }^{145}$ : „Die nach langer Zeit (sc. nach dem Tod des Verblichenen) vorgetragene Grabrede ist ein reines Enkomion." Wie ein solcher Epitaphios Logos bzw. ein solches Enkomion rhetorisch aufzubauen ist, wird von Menander etwas weiter unten, immer noch unter der Überschrift „Über die Grabrede“, genau beschrieben ${ }^{146}:$ „Du sollst im Enkomion preisen unter Verwendung aller zum Enkomion gehörigen Themen: des Geschlechts, der Geburt, der Natur, der Erziehung, der Bildung, der Umgangsformen. Die Natur aber sollst du in zwei Abschnitte einteilen, in einen über die Schönheit des Leibes, den du zuerst bringst, und in einen über die Vollkommenheit der Seele. Du sollst dies durch die drei folgenden Abschnitte bekräftigen, ich meine durch die Erziehung und die Bildung und die Umgangsformen. Wenn du nun sein Enkomion durch einen jeden dieser Abschnitte ausarbeitest, sollst du in Bezug auf die Erziehung sagen,

144 Vgl. dazu Aigrain, Hagiographie 123; Holl, Form 249-269.

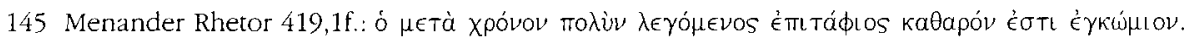

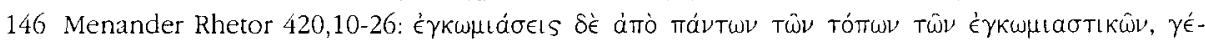

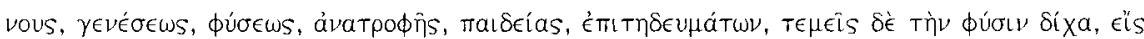

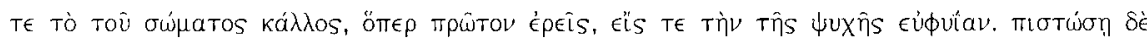

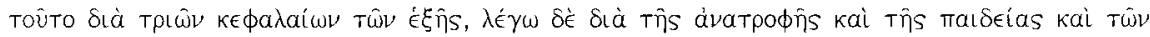

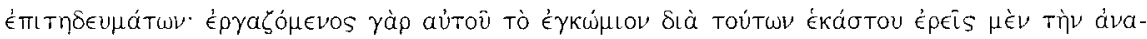

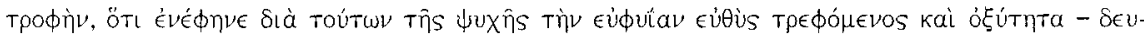

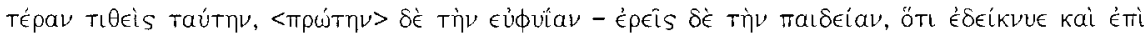

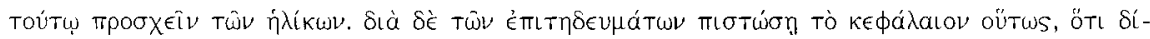

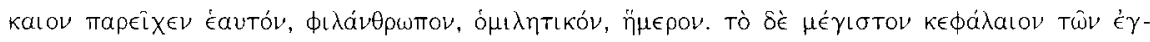

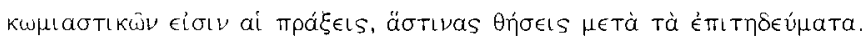


daß er darin Vollkommenheit der Seele zeigte, sobald er heranwuchs, und Erhabenheit - diese stellst du an die zweite Stelle, an die erste aber die Vollkommenheit. Im Hinblick auf die Bildung sollst du sagen, daß er auch darin seine Altersgefährten übertraf. Durch die Umgangsformen mache den Abschnitt folgendermaßen glaubhaft, indem du sagst, daß er sich als gerecht erwies, als menschenfreundlich, als umgänglich und milde. Der größte Abschnitt aber des Enkomions sind die Taten, die du nach den Umgangsformen bringst."

Dies ist eine bündige Zusammenfassung der Vorschriften für den rhetorischen Aufbau eines Enkomions, die Menander an anderer Stelle, nämlich in seinen Ausführungen zum Basilikos Logos, noch um die Bestandteile des Prooimion und des Epilogos ergänzt und dort auch wesentlich ausführlicher darlegt ${ }^{147}$. Aus all dem ergibt sich eine rhetorische Norm für den Aufbau eines Enkomions, die sich folgendermaßen zusammenfassen läßt:

Aufbau eines Enkomions (nach Menander Rhetor):

1. Proöm

2. Heimat, Elternhaus, Geburt (Patris, Genos, Genesis)

3. Natur (Physis)

4. Erziehung (Anatrophe)

5. Umgangsformen (Epitedeumata)

6. Taten (Praxeis), enthält auch Tugenden

7. Epilog

Nach der Untersuchung einer großen Zahl von Viten kann nicht der geringste Zweifel daran bestehen, daß der rhetorische Aufbau einer byzantinischen Heiligenvita genau diesen rhetorischen Normen der Komposition eines Enkomions folgt. Freilich lassen sich in Einzelfällen Abweichungen feststellen, jedoch bleiben diese die Ausnahme. In der Regel werden diese rhetorischen Normen beachtet und der Aufbau der Heiligenviten an ihnen orientiert ${ }^{148}$.

Ein Beispiel mag dies abschließend illustrieren: Die ältere Vita des Metropoliten Euthymios von Sardeis (BHG 2145; ${ }^{* 751 / 54,} \dagger$ 831), die von der Hand des Patriarchen Methodios I. stammen soll ${ }^{149}$, hält sich nicht an die antike Vorschrift, daß die Narratio des Enkomions mit der Erwähnung der Herkunft, des Geschlechts und der Geburt des Besungenen zu beginnen habe, sondern setzt

147 Menander Rhetor $368,8-377,30$.

148 Dies wird etwa auch durch das Inhaltsverzeichnis der Materialsammlung widergespiegelt, deren Aufbau ja gewissermaßen eine Abstraktion des üblichen Aufbaus der Heiligenviten darstellt.

149 Zu dieser Problematik und dem Verhältnis dieser Vita zu BHG 2146 vgl. PMBZ, Prolegomena 616 . 
ziemlich unvermittelt mit dem zweiten Konzil von Nikaia 787 ein, einem Zeitpunkt, an dem der Heilige bereits zwischen 33 und 36 Jahre alt war. Der Verfasser dieser Vita fühlte sich bemüßigt, auf diesen Umstand schon im Proöm hinzuweisen. Dort finden sich dann wortreiche Erklärungen, die die Auslassung dieser Angaben rechtfertigen sollen: Zum einen seien ihm diese Dinge nicht bekannt, zum anderen steuerten sie nicht notwendigerweise zur Erbauung der Seele bei. Er beginnt dann mit dem Konzil von 787 (welches das Verbot der Ikonenverehrung aufhob). Dies scheint auf den ersten Blick eine originelle Lösung ${ }^{150}$, die den Verfasser der Pflicht enthob, die Eröffnung des Enkomions mit inhaltsleerer Topik zu füllen, und es ihm erlaubte, sogleich zu seinem eigentlichen Gegenstand, nämlich der Darstellung des Euthymios als eines der Vorkämpfer für die Ikonenverehrung, zu kommen. Allerdings empfand der Verfasser selbst anscheinend die Abweichung von der rhetorischen Norm in diesem Falle doch als so gravierend, daß er es für notwendig erachtete, im vorab darauf hinzuweisen und sein Verfahren zu rechtfertigen.

Das Problem wird noch deutlicher, wenn man die spätere Vita des Euthymios (BHG 2146) betrachtet. Der Verfasser dieser Vita, der Mönch Metrophanes, benutzte nämlich offenbar die ältere Version der Vita als Vorlage. Gestützt auf diese Quelle, konnte folglich auch er keine Angaben zu Geschlecht, Geburt und Herkunft des Euthymios machen. Auch er empfand dies wohl als mangelhaft und spürte das Bedürfnis, sich dafür an passender Stelle zu rechtfertigen. Er tut dies jedoch nicht im Proöm, sondern beginnt sein Enkomion mit Topik: Die Heimat des Euthymios sei das himmlische Jerusalem, seine Mutter die Tetraktys

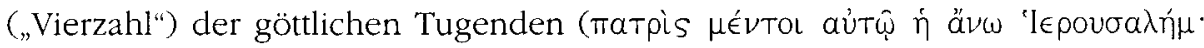

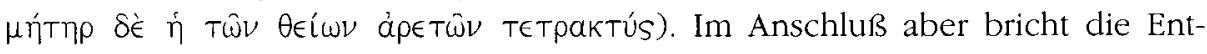
schuldigung für sein Abweichen von der antiken Norm aus ihm heraus: „Wenn nun aber die Zusammenstellung nicht nach der heidnischen ${ }^{151}$ Gewohnheit $(=$ Norm) der Enkomia geraten mag, indem sie zeigt, wie und von wem er aufgezogen wurde oder in welcher Stadt er am Anfang wohnte, so soll niemend

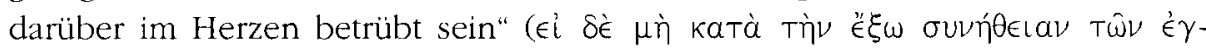

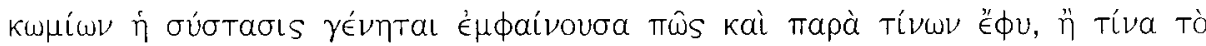

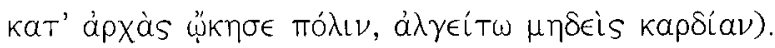

150 Im Zuge des Strebens nach variatio waren ja die Aufhebung und Brechung, also das Spiel mit den Normen der Antike, durchaus zulässig

151 Gemeint sind die antiken Vorschriften cler Rhetorik; Tà ${ }^{\epsilon} \xi \omega$ bezeichnet, im Gegensatz zu Tà $\dot{\eta} \mu \omega \hat{\omega} \nu(\gamma \rho \dot{\mu} \mu \mu a \tau a)$, in den byzantinischen Texten stets die nichtchristliche, heidnisch-antike Literatur. 


\section{\4. Zur Typologie}

In der Forschungsliteratur findet sich des öfteren die Einteilung der Heiligenleben in "literarische" oder (nach Ehrhard) "rhetorische" Viten und "monastische" oder (nach Ehrhard) „volkstümliche"152 Viten. Ehrhard teilte die Viten in drei Gruppen ein ${ }^{153}$ : „die rhetorischen, volkstümlichen und liturgischen." Als „liturgische Viten" bezeichnete er die Kurzviten in den Synaxaren und Menologien, die uns hier nicht interessieren müssen. Zu den "rhetorischen Viten“ bemerkte Ehrhard: „Die rhetorischen tragen den Charakter der Kunstlitteratur an sich; sie sind von rhetorisch und stilistisch geschulten Autoren verfaßt und richten sich an das gebildete Publikum der höheren Stände." Als Muster führte er dann die überarbeiteten Viten des Symeon Metaphrastes an. Zu den „volkstümlichen Viten" vermerkte er: „Die volkstümlichen Heiligenleben waren für die weiten Volkskreise bestimmt; sie sind einfach und schlicht geschrieben und gefallen sich besonders in der Erzählung von Wundergeschichten, die zu jeder Zeit vom Volke mit Vorliebe gelesen wurden. In der Regel stammen sie jedoch nicht aus den Volkskreisen selbst; sie wurden auch von Gebildeten geschrieben, die aber einen offenen Sinn für die Bedürfnisse des Volkes hatten." Treffende Beispiele dafür waren für Ehrhard die Viten aus der Feder des Leontios von Neapolis. Ehrhards Einteilung in "rhetorische" und „volkstümliche" Viten ist also anscheinend eine Einteilung nach dem unterstellten Zielpublikum der Viten. Die Bezeichnung der Gruppen ist allerdings auch bei Ehrhard nicht ganz stimmig, da sowohl "rhetorische" als auch "volkstümliche" Viten, die ja in erster Linie durch den Stil unterschieden werden, insofern „liturgische" Viten sein konnten, als auch sie einer liturgischkatechetischen Verwendung dienten ${ }^{154}$.

Ihor Ševčenko war in einer Untersuchung zu den Stilebenen der byzantinischen Prosaliteratur dafür eingetreten, die klassische rhetorische Einteilung in drei Stilebenen, nämlich ",high", „middle" und „low", auch für die byzantinische hagiographische Literatur zu übernehmen und folglich drei Klassen von Viten anzunehmen ${ }^{155}$. Auch für Ševcenko waren die überarbeiteten Viten des Symeon Metaphrastes Verteter des hohen Stils, die größtenteils aus dem mittleren Stil in den hohen umgearbeitet worden seien ${ }^{156}$. Ševčenko stieß in seiner Untersuchung aber offenbar bereits an die Grenzen seiner Einteilung, da er es für not-

152 Vgl. dazu I. Ševcenko, Observations on the Study of Byzantine Hagiography in the Last HalfCentury or Two Looks Back and One Look Forward, Toronto 1995, 16f.: gegen die Bezeichnung der Hagiographie als „populäre“ Literatur.

153 Ehrhard, Hagiographie 181.

154 Vgl. dazu oben S. $372-377$.

155 I. Sevcenko, Levels of Style in Byzantine Prose, in: JÖB 31/1 (1981) 289-312, hier bes. 291f.

$156 \mathrm{Vgl}$. Ševčenko a. a. O. 300-303. 
wendig erachtete, zusätzlich zu den drei genannten Stilebenen die Unterkategorien "lower middle style" und "super-high style" einzuführen ${ }^{157}$.

Unlängst hat Christian Høgel die stilistischen Überlegungen Ševcenkos hinsichtlich der Hagiographie relativiert, indem er zu Recht feststellte, daß die byzantinischen Autoren und Auditorien wohl kaum mehr als zwei Stilebenen wahrgenommen haben werden ${ }^{158}$. Høgel sprach sich, in Anlehnung an Ehrhard, wiederum für zwei Stilebenen aus, nämlich den „simple style“ und den „high style". Allerdings finden sich auch bei Høgel bereits gelegentliche Zweifel an der Richtigkeit dieser Einteilung ${ }^{159}$

Alle diese Einteilungen sind nämlich grundsätzlich problematisch! Zum Teil schon deshalb, weil die Begriffe nicht genau geklärt sind: Was ist "literarisch“, was ist "monastisch"? Was sind die Kriterien der Unterscheidung? Vitenheld, Stil, Verfasser, Milieu der Abfassung, vermeintlicher Zweck oder vermeintliches Publikum, Historizität? Beispielsweise finden sich sowohl unter den sogenannten literarischen wie auch unter den sogenannten monastischen Viten solche, deren Vitenheld nachweislich historisch ist, und solche, deren Vitenheld sonst nicht historisch belegt ist. Eine Einteilung der Viten nach dem Kriterium der Historizität der Vitenhelden muß dann folgerichtig die Unterscheidung in literarische und monastische Viten ignorieren ${ }^{160}$.

Es kann nicht bestritten werden, daß manche Viten rhetorisch anspruchsvoll und andere eher schlicht gehalten sind ${ }^{161}$. Es kann auch nicht bestritten werden, daß manche Viten nicht in einem monastischen Umfeld entstanden, andere aber durchaus. Jedoch liegen diesen Unterscheidungen bereits verschiedene Einteilungskriterien zugrunde, so daß „rhetorisch/literarisch“ nicht a priori einen Gegensatz bildet zu "monastisch/volkstümlich“. Die Bezeichnung der beiden Klassen verdeutlicht lediglich folgende Sachverhalte: Innerhalb des gesamten Bestands ist 1. unter dem Aspekt des Stils eine Anzahl von Heiligenviten rhetorisch bzw. literarisch anspruchsvoller gestaltet als der Durchschnitt, und ist 2. unter dem Aspekt des Entstehungsumfelds und des vermeintlichen Zielpublikums eine Anzahl von Heiligenviten in einem monastischen Milieu entstanden; diese Viten sind oft in einem schlichteren Stil und anscheinend für ein einfacheres Publikum (Mönche) geschrieben. Diese beiden Sachverhalte stehen nicht

157 Vgl. Sev̌enko a. a. O. 291: "lower middle style“, 302: „super-high style".

$158 \mathrm{Vgl}$. Høgel, Symeon 23: „Byzantine authors and audiences hardly perceived more than two levels".

$159 \mathrm{Vgl}$. Høgel, Symeon 27: „we are left with hundreds of mostly anonymous martyria, lives, miracle stories etc. in simple style, by far outnumbering the group of high-style writings" u. ö.

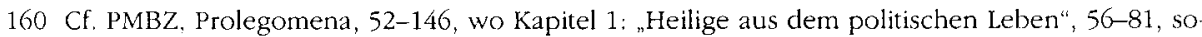
wohl sogenannte literarische als auch sogenannte monastische Viten vereint.

161 Vgl. Rapp. Hagiographers 39-42. 
notwendigerweise in einem Gegensatz! Auch eine rhetorisch anspruchsvolle Vita kann in einem Kloster und für Mönche geschrieben worden sein, auch eine Vita in einfacherer Umgangssprache kann außerhalb eines Klosters entstanden $\operatorname{sein}^{162}$.

Es mag aus praktischen Gründen hilfreich oder sogar notwendig sein, darauf hinzuweisen, daß die Viten sich in Hinsicht auf ihren Stil stark unterscheiden, daß manche Viten aus einem monastischen Umfeld stammen, andere dagegen nicht. Elemente der Rhetorik ("rhetorische Viten") finden sich in unterschiedlichem Ausmaß in beinahe allen Viten, und Literatur ("literarische Viten") sind sie ohnehin. Nach dem Hinweis auf diese Unterschiede kann jedoch vor allen Dingen die übergroße Vielfalt der Heiligenviten kaum genug betont werden $^{163}$. Diese Vielfalt führt dazu, daß der Übergang von einer bestimmten typischen Gruppe von Viten zu einer anderen bzw. von einer Stilebene zur anderen völlig fließend verläuft. Aus diesem Grunde läßt sich eine methodisch saubere Einteilung in zwei oder mehrere Gruppen von Heiligenleben nicht durchführen.

162 Man beachte jedoch die oben getätigte Feststellung, daß die überwiegende Zahl der byzantinischen Heiligenviten für einen liturgisch-katechetischen Gebrauch bestimmt war und in einem monastisch-klerikalen Umfeld entstand, s. oben S. 372-377. - Zu einer ähnlich unhaltbaren Unterscheidung in einer anderen Gattung der byzantinischen Literatur, nämlich der zwischen „Historiographie" und "Chronistik" auf dem Gebiet der Geschichtsschreibung, vgl. H.-G. Beck, Zur byzantinischen "Mönchschronik", in: Speculum Historiale, Freiburg 1965, 188-197 (= clers., Ideen und Realitaeten in Byzanz. Gesammelte Aufsätze, London 1972 [Variorum Reprints], Nr. XVI).

163 S. dazu noch unten S. 408-410. 